\title{
Smart Toys in Early Childhood and Primary Education: A Systematic Review of Technological and Educational Affordances
}

\author{
Vassilis Komis ${ }^{1, * \mathbb{D}}$, Christofors Karachristos ${ }^{1}$, Despina Mourta ${ }^{1}$, Konstantina Sgoura ${ }^{1}$, Anastasia Misirli ${ }^{1}$ (D) \\ and Alain Jaillet ${ }^{2, *}$ \\ 1 Department of Early Childhood Education, University of Patras, 26500 Patra, Greece; \\ karachrist@g.upatras.gr (C.K.); despoinamourta@gmail.com (D.M.); konstantinasgour@gmail.com (K.S.); \\ amisirli@upatras.gr (A.M.) \\ 2 INSPÉ de l'académie de Versailles, CY Cergy Paris Université, 95000 Cergy, France \\ * Correspondence: komis@upatras.gr (V.K.); alain.jaillet@u-cergy.fr (A.J.)
}

Citation: Komis, V.; Karachristos, C.; Mourta, D.; Sgoura, K.; Misirli, A.; Jaillet, A. Smart Toys in Early Childhood and Primary Education: A Systematic Review of Technological and Educational Affordances. Appl. Sci. 2021, 11, 8653. https://doi.org/ 10.3390/app11188653

Academic Editor: Andrea Prati

Received: 12 July 2021

Accepted: 12 August 2021

Published: 17 September 2021

Publisher's Note: MDPI stays neutral with regard to jurisdictional claims in published maps and institutional affiliations.

Copyright: (c) 2021 by the authors. Licensee MDPI, Basel, Switzerland. This article is an open access article distributed under the terms and conditions of the Creative Commons Attribution (CC BY) license (https:// creativecommons.org/licenses/by/ $4.0 /)$.

\begin{abstract}
The present paper presents a systematic review of the last 30 years that concerns records on Smart Toys and focuses on toys regarding early childhood and primary education children (3-12 years old). This paper aims to analyse and categorise smart toys (50 articles) in terms of their technological and educational affordances. The results show that the toys are designed based on four main technological affordances and their combinations. The educational affordances of smart toys are studied in terms of different use modes and their learning objectives aimed to identify specific objectives in different subjects and objectives based on transversal competencies such as problem solving, spatial thinking, computational thinking, collaboration and symbolic thinking. Finally, with the multiple correspondence analysis, the correlations between smart toys' individual technological and educational affordances are grouped with the evolution of affordances related to their development date. In conclusion, in recent years, smart toys concern special sciences (programming) and some 21st-century skills (STEM and computational thinking). In contrast, in the first 20 years, the interest focused more on transverse skills, such as collaboration, emotional thinking, symbolic thinking, story-telling and problem solving.
\end{abstract}

Keywords: smart toys; affordances; early childhood and primary education

\section{Introduction}

Play as an activity has always been an essential and integral part of the human culture. The child's involvement with play is vital in early childhood as this has a significant role in the child's physical, psycho-emotional, social and cognitive development [1]. Through play, children can act freely and express their feelings, communicate, explore the world around them and learn in a fun way. Levin and Rosenquest [2] highlighted that play helps children control their actions and interact with other people and encourage their expression, imagination, and interests.

The pedagogical value of play is acknowledged by international organizations teaching children of early childhood and primary education [3]. Such organizations offer educational programs whose quality depends on the stimuli obtain from the environment, which should enhance their physical and socio-emotional development. Play is a crucial element in this direction. Regarding the relationship between play and education, in particular, the term "playful learning" is found in the literature referring to the use of play through guided activities aiming at children's cognitive development [4]. Thus, we can direct children to fun and creative paths that enhance learning and convey the joy of discovery through easy-to-implement projects. 


\subsection{Play, Toy and Game}

There is no clear definition of what play is and how it contributes to children's evolution and character formation. However, Meckley [5], states that play includes characteristics, such as freedom in children's choices, activation of the child's inner motivations, satisfaction and pleasure, the child's self-action within it and finally, the meaning of playing in them.

Play includes a wide range of voluntary, internally driven activities with reactional pleasure and fun [6]. In addition, play is mainly associated with children without this, meaning that it could not occur at any stage of human life. There are different types of play, such as natural/play (movement, strength etc.), social play, creative constructions play and imaginary play. Combinations of play can also result from the above, such as social and fantasy play together. In addition, play as an activity can be both outdoors and indoors.

The term toy as an object identifies all those physical objects used for the physical activity of play [7]. The toy-objects can be made especially for play, such as the chessmen of a board game, or simple objects used as toys depending on the user's mood, such as an iron wreath, which can be transformed into a steering wheel.

The organised game is a structured form of play-activity mainly used for children's entertainment and sometimes as an educational tool [8]. The key elements that make up the concept of organised play are the specific goals set, the rules, the challenges and the interaction between the participants. Organised games usually require mental and/or physical stimulation and, in many cases, help the user acquire skills.

There is a growing interest in the field of human-computer interaction for different types of games and the interaction of technology and computing intelligence into them. Integration involves either technological support for play as an activity (such as using GPSbased technologies and communications in outdoor games) or integration of in-game object technologies that are reportedly used regarding the gaming activity. An example could be a child doll with built-in communication sensors. Below are examples of integrating computer intelligence into traditional toys and toy environments in recent decades. An attempt is also made to define the term smart toy as it has been researched in previouos years. Finally, research questions arise from a review of international scholarly activity on the relationship and interaction between children and smart toys.

\subsection{A Definition of Smart Toys}

The development of digital technologies and the Internet over the last decades has also affected the toys sector. As toys play a significant role in children's evolution, the scientific community has been methodically involved in exploring the application of technology on them and how children interact with toys. This research is part of the broad area of child-computer interaction (CCI). The CCI has been evolved since the early 1980s. Over the years, research in this field has changed in terms of the tools used, including children's age range, needs, interests and socio-economic environment [9]. According to Read and Bekker [10], the child-computer interaction concerns the "Study of activities, behaviours, concerns and abilities of children as they interact with computer technologies, often with the help of others (mainly adults) in situations that they partly control". This scientific area studies, among other things, the application of technology in traditional toys in order to optimize the interaction of children with them. The age range of children studied in this field ranges between 2 and 13 years old.

Mitchel Resnick and his research group from Lifelong Kindergarten of MIT was one of the first researchers that talked about digital objects aimed at helping children to learn [11]. Through this program, which he led, he tried to study how the construction theory of learning (constructionism), developed by Seymour Papert [12], could be implemented by technological means. This research resulted in a series of educational tools called "Digital Manipulatives", which incorporated computing capabilities into traditional toys, such as cubes and balls. Thus, these digital objects are considered the first smart toys. 
In the bibliography, the term smart toys is used to describe toys on which digital features such as software or digital materials such as sensors have been added $[13,14]$. These types of toys provide a more interactive environment than traditional toys, in which children can develop their cognitive, social and behavioural skills [15]. As Lampe and Hinske point out [1], the enrichment of traditional toys with features enables them to develop their imagination in a more creative environment. In another definition, smart toys are those toys that incorporate microcontrollers and can communicate with computers [16]. Since new technological tools are constantly developing, we can say that the definition of smart toys is constantly changing. In addition, the term smart toys can be defined as a type of toy that incorporates tangible objects and electronic components such as sensors and accelerometers and enables two-way interaction between the child and the toy. In this way, these toys can perceive the world around them and react accordingly [15]. They also support communication skills by allowing designers to integrate digital elements into traditional toys, such as 3D objects, which were previously only available in electronic toys [17]. Another modern definition of smart toys based on current technological data and adding to the ones mentioned above refers to these as wireless-networked, sensorenhanced toys with a data management system. For example, such a toy can provide vocal, visual, kinetic or other feedback and recognise the voice, physical movements and space placement [18]. Numerous studies were carried out to evaluate such toys, mainly in terms of their effect on children. For example, Kara et al. [13,19] developed smart toys to support digital storytelling activities. Their studies showed a positive effect of these toys on children. At the same time, these toys enable children to learn through exploration, trial and error, collaboration, experimentation and simulation.

However, it should be noted that not all technology-equipped toys are smart toys. There should be a clear distinction between smart toys and toys that carry technological elements. Few references are found in the international bibliography on guidelines regarding characterising toys with technological elements as smart. As reported by Cagiltay et al. [15], a key element that differentiates smart toys from toys that simply have electronic features is its purpose. For example, a mobile phone toy plays tones when the child presses its buttons. This fact does not make it a smart toy as it does not serve any purpose, like children interacting with each other, but its sole purpose is to entertain children.

Since smart toys incorporate technological elements, they offer some advantages compared to traditional toys [13]. A fundamental advantage is that they provide children with a more creative environment, stimulating their imagination. At the same time, a smart toy increases the degree of interaction of children both with the toy itself and with each other, helping them to socialise. In addition to these advantages, these types of toys can be used for educational purposes. Those toys enable teachers to use the enhanced capabilities they incorporate as long as they understand the nature of these toys in the educational process [14] and can balance traditional toys [20]. For example, such "scientific" toys were used to teach physics, chemistry and biology [21]. Finally, smart toys are used in education to enhance the social skills of children with mental disabilities [1].

\subsection{Review of Literature}

Numerous studies are carried out regarding integrating technology in objects and toys intended for early childhood and primary school children. Usually, toys such as those mentioned above can be used for various purposes such as entertainment, socialization, education, etc.

The smart toys used as digital storytelling tools to record children's ideas through playful processes present great research interest. One of the first examples of smart toys introduced was Rosebud [22]. Rosebud is an interface that extracts digital narratives through children's interaction with various technologically enhanced physical objects enabling them to write, modify and share their ideas. Similarly, in MIT's multimedia lab, Ryokai and Cassel developed in 1999 the StoryMat, a collaborative digital storytelling system [23]. The StoryMat enables the recording of children's voices and movements. 
Evaluations of this toy showed that children produced more fictional stories compared with when they used traditional toys. The Dolltalk is an interface that encourages children to create their personal stories [24]. It uses voice and movement recognition techniques. Then, it reproduces these stories using different characters in the story. The toy used tangible technology features. The StoryTech is a "smart toy" of digital story-telling that combines the real with the digital world [13]. Children handle real-world objects and interact in this way with virtual world objects in order to create their own stories. It is based on radio frequency identification (RFID) technology for communicating physical objects with digital counterparts. Another example of such toys is TOK (Touch, Organize, Create) [25]. TOK uses natural blocks to handle virtual data through a tangible surface in order to create digital narratives by early childhood and primary school children. A key element of the TOK is the fact that children can work together using physical objects together. Similar digital storytelling systems for children are Tell-Tale [26], t-words [25] and jabberstamp [27].

Another category of smart toys is those developed to assist the educational process. An educational toy named Curlybot, was developed to help children of at least four years old understand advanced mathematics (for example, geometry) and computer concepts through play [28]. In 2007 at the MIT's multimedia laboratory, Merill et al. [29] presented the Siftables platform, an innovative electronic cube platform that combines wireless technology, sensors and a graphics display. By interacting with the cubes, children can create their own drawings, deal with simple mathematical problems and create their own words. The SMART is an augmented reality system used to teach students of the 2nd grade. Specifically, children explore 3D simulation models through play [30]. After real-time research, the results showed that the system significantly helps the learning process of mainly weak students. Another example of this category of toys is Educational Magic Toys-EMT, which constitute a series of toys that have incorporated augmented reality features such as 3D objects to introduce children aged 5-6 years old in basic concepts, such as colours, numbers and animals [14]. In the DigiTile project, students are called to solve mathematical challenges by placing appropriate shares on a tangible surface [31]. A similar example is TanTab which consists of a tangible surface on which tangrams are placed and aims to explore geometric concepts [32]. In 2014, Fleck, Simon and Bastein presented an augmented reality learning environment called AIBLE, which was designed to teach basic astronomical phenomena to primary school children [33]. The innovation of this environment lay in the use of 3D augmented reality models that students experimented with, interacting with physical objects on which digital signs (tangible markers) have been added. These features give students the chance to perceive the motion of the planets in real space.

Studies related to augmented reality in teaching educational subjects were carried out with positive results regarding the potential benefits of augmented reality in enhancing the teaching of various subjects [34]. Cascales et al. [35] analysed the purpose of using augmented reality content in early childhood students as a tool to improve their learning. To this end, they developed and used an application designed to incorporate augmented reality content by using a camera so this content can be viewed on objects. Hsieh and Lee [36] conducted a similar study, which proposed ARELS, an English-learning system using augmented reality technology addressed to early childhood children. The SketchPlay-Learn system is an augmented surface that is paper-based and assists children in learning the principles of light behaviour [37]. Students have to complete an activity drawn on paper and then observe the visual feedback on the paper. The I/O Brush is a design tool aimed at young children of at least four years old and enables them to explore the colours and textures they encountered in everyday objects and draw with them [38]. It looks like a regular brush that incorporates a camera with light and touch sensors. With the brush, the child can choose the colour from any surface. The system developed by Campos and Pessanha [39], was based on tangible technology and concerned early childhood children. The evaluation of the system focused on the positive effect of the use of tangible augmented 
reality surfaces in the educational process, but also in the communication of students with each other. An electronic board game based on tangible technology called TagTiles was presented and evaluated by Verhaegh et al. [40] to improve children's motor, cognitive and social skills. It uses sensor networks that adapt to toys. Zabala et al. [41], developed the Arduino Etoys platform, a visual programming environment that connects the virtual with the real world. With Etoys, children can program real-world objects (such as robots) to perform various actions or feel the world and use this information to control virtual world objects. Lampe and Hinske [1], presented an environment-toy of augmented reality, which provides interactive learning skills. As it was called the Augmented Knight's Castle, relied on the Radio Frequency Identification (RFID) technology to identify the elements on the toy. With this particular environment, interactive learning experiences (for example, teaching songs and poems) can be integrated into the toy. Kubicki et al. [42] developed a tangible desktop surface called TangiSense (with RFID technology) that allows users to relate information to specific behaviours in order to handle tangible objects. More specifically, children should place objects in the correct coloured areas. Then, through an additional tangible object called "Magician" the platform analysed the completed areas and provided feedback to the children and their teacher. Another example of an augmented reality toy is Powerball [43]. It is addressed to children aged 8-14 years and aims at bringing together children with or without learning difficulties by enhancing social interaction through play.

The study of Lin et al. [44] aims to investigate the effects of didactic approaches on guiding early childhood children to learn computational logic and programming concepts. A teaching methodology was designed to develop the students' cognitive skills, which adopts the learning approach based on the smart toy through the Tangible User Interface and aiming to enhance students' learning performance and interests.

Based on the assumption that students build knowledge by interacting directly with the environment and cognitive objects taking a leading role in learning activities, this perspective was sought to verify in their study conducted by Pan et al. [45]. For example, using three-dimensional letters (AR technology), they concluded that students could understand the alphabet letters faster.

Hybrid interfaces that combine augmented reality skills with tangible interfaces are found in the bibliography and mark the way for more intelligent toys. However, today, few smart toys combine such characteristics and even less have been evaluated in terms of their role in children's physical, psycho-emotional, social and cognitive development. Examples of such interfaces mainly used in the educational process to help children understand complex phenomena and concepts in the field of astronomy, optical waves and brain activity are Helios, Hobit and Teegi [46].

Many smart toys and systems have been developed in recent years to introduce algorithmic thinking and teach basic programming concepts. The program called Toys of Tomorrow, as well as the program called Lifelong kindergarten of MIT's multimedia laboratory, focused on integrating technology into traditional toys to make them more intelligent and interactive [47]. Important educational tools and toys have emerged from these programs, such as LEGO/Logo, which combines Lego bricks with the Logo programming language $[48,49]$. The programmable bricks are a continuation of LEGO/Logo and incorporate technology over the bricks themselves [50,51]. Each programmable brick disposes of outputs for motor controls and inputs for recording values from sensors. The Code Bits is a tangible programming tool that is paper-based. Students create programs using these paper-based tangible commands of the environment and then, with the help of an application running on a smart device and which uses the camera, execute the code [52]. The code execution involves augmented reality toys that help children to develop their computational thinking. In a relevant paper Horn, Crouser and Bers [53] focus on how tangible interactions can support or improve the educational process compared to the traditional methods. Data from these studies comparing the use of tangible and mouse-based interactions. The core tools of both three studies are the use of a tangible programming language named Tern. Instead of using a mouse and a keyboard, students use wooden 
command blocks to program robotic constructions. Through some visual recognition software, the robotic construction read the commands in series and executes them.

Finally, in the bibliography we often find smart toys of playful children's environments that can be used either in organised educational activities or free play. These environments make it possible to design activities for various educational objects and for different skills, the children will have to build. One such example is called "Crafti" [54]. "Crafti" is the acronym derived from the "Method for the Control and Regulation of Physical Activity of Children through a Novel Platform for Full-body Interactive Experiences called the Interactive Slide". It is an interactive slide that is enhanced by interactive technologies. A motion recognition system records children's actions and movements enabling them to play in a more interactive environment. The infrastructure allows the development of many toys on this surface without the need to modify the surface. This project aims to find and evaluate a method of detecting and controlling children's physical activity through their interaction with the environment. Similar research was also carried out in the project entitled "Smart Kindergarten" which addressed to early childhood children and aimed at creating "natural" learning environments, incorporating sensors in everyday objects that communicate with the child via wireless networks [18]. Dimitriou and Dasygenis [55] presented a doll-toy with a built-in sensor system that aims to monitor the child's emotional state and parental control. Through a live image transmission from a built-in camera on the toy, the child's facial expressions are analysed from a remote computer and then the system is fed back with a suitable song to keep the child happy and calm. Such systems incorporate Internet of Things (IoT) features as the toy communicates over a network with a remote device to send and receive data. A similar study was conducted by Ganesan et al. in 2010, who incorporated wireless sensors into traditional toys [56]. In addition, Westeyn et al. [57] developed a play system with built-in wireless technology that supports the automatic recording, recognition and quantification of child behaviours for retrospective analysis.

\subsection{Rational and Research Questions}

The present paper aims at the systematic review of non-commercial smart toys that have been developed or can be used in early childhood and primary education (from 3 to 12 years old) in the last 30 years or so. As there is no previous literature review in the field, studying these toys aimed to identify the structural elements in the field, such as definitions for smart toys and categories based on technological and pedagogical aspects.

This review is made in two axes: in the axis of their technological features (technological affordances) and in the axis of their possible educational uses (educational affordances).

Based on these axes, the paper's purpose is to answer the following questions:

(a) How are smart toys categorized based on the technological (and other) elements they incorporate?

(b) How are smart toys categorized based on the educational framework where they have been developed and used?

\section{Materials and Methods}

This paper reviews the international bibliography on smart toys in early childhood and primary education and more specifically in articles that have been published in scientific journals and in the proceedings of international conferences over the last 30 years. The bibliography review was based on the guidelines proposed by Kitchenham [58]. Research manuscripts reporting large datasets that are deposited in a publicly available database should specify where the data have been deposited and provide the relevant accession numbers.

Google Scholar was used as a starting point for a bibliographic research. Initially, the term "educational technology" was used. The purpose of this type of keyword search was to explore the most key databases that could be used later as search sources. Based on the results, records were sought from the following databases: 
- $\quad$ ACM (Association for Computer Machinery)

- IEEE Xplore Digital Library (Institute of Electrical and Electronics Engineers)

- JSTOR

- Sciencedirect

- $\quad$ SpringerLink

- Taylor and Francis

In some cases, toys were selected, which were not registered in any of the above databases, but whose contribution to the study, based on the bibliography, was considered significant.

In this context, the review was reported according to PRISMA guidelines [59]. The PRISMA flow diagram showing the flow of search in identification and screening of sources for analysis was presented in Figure 1.

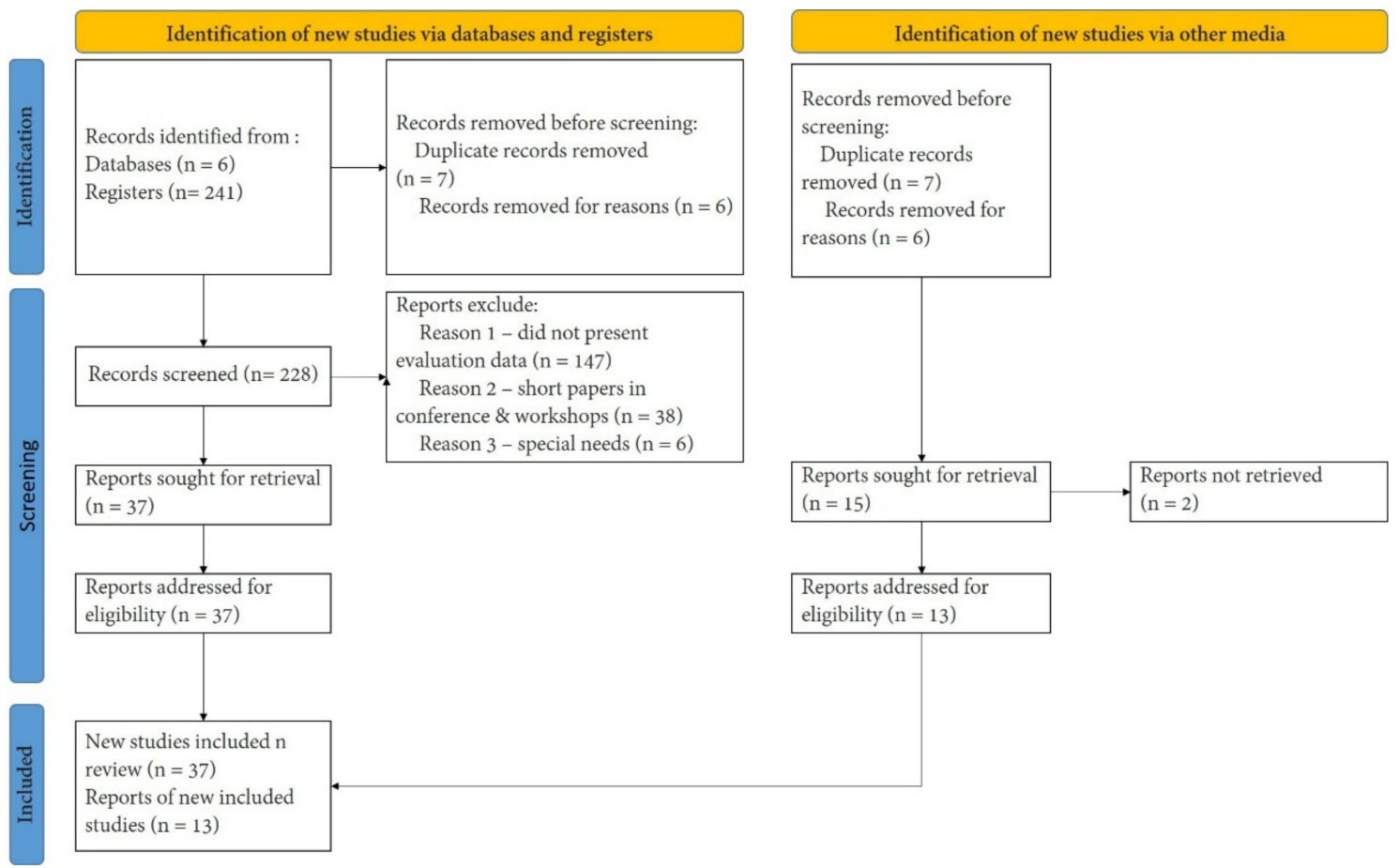

Figure 1. PRISMA 2020 flow diagram for updated systematic reviews which included searches of databases, registers and other sources.

We found 241 records in databases searching. After duplicates removal, and records removed for other reasons we screened 228 records, from which we reviewed 228 full-text documents, and finally included 50 papers [each cited]. Later, we searched documents that cited any of the initially included studies as well as the references of the initially included studies. However, no extra articles that fulfilled inclusion criteria were found in these searches.

We excluded 191 studies from our review. All the records that did not present evaluation data of the smart toys they propose, the short papers in conferences and workshops and records regarding special needs.

\subsection{Determination of Key-Terms}

After coming up with the databases that would be used, we started searching with specific terms such as "Smart toys", "technology-based toys" [15], "Programmed toys" and "Robotic toys-Augmented reality toys".

The search was divided into 3 phases. In the first phase, searches were performed in the databases above using "Educational technology" terms. The purpose of this type of search with key-terms which are more general terms than those of smart toys was to 
investigate the suitability of the databases which could be used. In the next phase, the specific search terms mentioned earlier were used. Reports were collected whose relevance was derived from the title, summary, chronology and keywords that referred to them. At the same time, reports were sought, which were cited in the bibliography of the studies we study. In general, the search method was an iterative process based on:

- Test searches in databases with combinations of search terms that resulted from the research questions

- Searches for possible similar studies in the literature of the studies read.

\subsection{Selection Criteria}

General criteria:

- $\quad$ Studies published from 1991 until 2020.

- Studies describing the development of smart toys and their possible applications in the educational process (formal and/or informal).

- Special criteria:

- Non-commercial digital toys.

\subsection{Rejection Criteria}

All the records did not present evaluation data of the digital toys they propose, short papers in conferences and workshops and reports regarding special needs.

Finally, 50 articles related to 52 smart toys were selected and were included in the review. Thirty-nine of the toys were found in the databases of Table 1.

Table 1. Databases for the selection of smart toys.

\begin{tabular}{ccc}
\hline Databases & Number of Toys Selected & Smart Toy No \\
\hline ACM (Association for Computer Machinery) & 25 & {$[3-9,11-13,15,18,20,22,23,26,29,31,37-43]$} \\
\hline IEEE Xplore Digital Library & 2 & {$[2,25]$} \\
\hline JSTOR & 1 & {$[16]$} \\
\hline Siencedirect & 7 & {$[19,24,28,32,50-52]$} \\
\hline SpringerLink & 2 & {$[27,48]$} \\
\hline Taylor and Francis & 2 & {$[30,47]$} \\
\hline
\end{tabular}

All the selected articles were coded with a unique serial number $([1,2], \ldots$, see Table 2$)$. The assignment of the article to a number has been increasing based on the article's date.

Out of the 52 toys selected, 13 were drawn from University databases, such as Lego/logo toy (Resnick and Ocko [48], which was drawn from the MIT University Database).

\subsection{Categories of Analysis and Data Coding}

To create analysis categories and data encoding, the concept of affordance is used, as defined by Norman [60] and Salomon [61] after Gibson [62].

The concept of affordance refers to a property provided by the object itself and implies what we should or could do with the object in question. Affordances refer to the things made possible by a particular feature of an object.

In a more psychological approach, this concept is linked to the capabilities of tools and in this article, to the technological and educational capabilities of smart toys. The concept of affordance was first proposed by James J. Gibson [62], who wanted to describe the set of all the actionable properties of an environment. The action properties are objective but are directly related to the user who will use them. The capabilities of tools or technology objects are not always the same, even if they belong to the same category. A physical game usually does not provide the same capabilities as its digital counterpart. In addition, the 
same environment does not present the same possibilities of action to all its potential users, for example, a staircase does not make its possibilities of use understood by a baby.

According to the research questions, two main categories of analysis are proposed:

(a) Technological affordances related to a specific type of features of smart toys:

(a1) Tangible Features: (TF);

(a2) Augmented Reality Features: (AR);

(a3) Internet of Things Features: (IoT);

(a3) Sensor equipped Features: (SE).

(b) Educational affordances related to the educational framework (type of activity) developed and used and the learning objectives aimed at smart toys:

(b1) Type of activity:

- Organized educational activity OEA;

- $\quad$ Free game (FG);

- $\quad$ Both OEA and FG.

(b2) Learning objectives:

- Objectives for a specific subject, for example mathematical concepts, physics concepts, programming concepts)

- Objectives related to transversal competencies, such as problem solving, cooperation and symbolic thinking.

The above categories of analysis are further analysed.

\subsection{Technological Affordances}

Technological affordances refer to specific characteristics of smart toys that distinguish them from traditional toys or digital toys that do not have "smart features".

\subsection{Tangible Smart Toys}

Toys in this category incorporate tangible technology features through tangible user interfaces. The term tangible user interface was invented by Ishii and Ullmer [63] to indicate the interfaces that the user can appropriately handle with actions such as movement, rotation and pressure to interact with the virtual world. The possibilities offered by this technology enhance the real world and assist the educational process by providing innovative ways for users to interact with natural objects [64,65]. The only natural features offered by tangible interfaces enable collaborative learning in many new ways [66]. Another definition of tangible interfaces according to Shaer and Hornecker [67], is the following: "Interfaces that correspond to tangible representations of digital information, allowing users to literally grab data with their hands and affect functionality through natural handling of representations". It is a fact that many studies have been presented regarding toys that incorporate such features as they increase the degree of children's interaction with technology. Following the above definition of tangible user interfaces, we can refer to smart toys of this category as toys that interact with each other or with other systems by assigning tangible representations to digital information.

\subsection{Augmented Reality Smart Toys}

Augmented Reality Toys are traditional toys which are equipped with sensors, have computing power and allow creators to incorporate virtual reality elements on them, creating a mixed reality for the child. Augmented reality is a technology that introduces virtual elements such as 3D objects, sounds, text, video and images into real objects and in real time [35]. In the previous definition, we can add the ability to handle the above objects (Select, rotate, move etc.). A key feature of these toys, as well as toys that belong to the category of smart toys, should be the adaptation of their technological elements so that they are not perceived by children. In addition, these features that make the toy smart should not affect its functionality in case of absence. Augmented reality, which allows 
seamless connection between the elements of the natural and virtual worlds, is one of the latest technologies used in education. It can enable children to study 3D objects from different points of view and help them understand different concepts [68]. At the same time, children learn in a more fun and playful way and can be taught subjects that could not be taught in real conditions.

\subsection{Sensor Equipped Features}

Sensor Equipped Toys are those toys that have built-in sensors. The sensors can record measurements of anything in the environment, allowing the toy to learn, behave according to predetermined patterns and change its actions according to environmental stimuli. In addition to the sensors, these toys also incorporate microprocessors or microcontrollers, a memory system, storage area and input-output devices [69]. The evolution of Sensor Equipped Toys is IoT Smart Toys which are described below.

\subsection{Internet of Things Smart Toys-(IoT Smart Toys)}

According to Manches et al. [70], Internet of Smart Toys are those toys that can be connected through a network and interact with software. Their main feature in relation to smart toys of other categories is their ability to interconnect either with each other or with other systems through local or wider networks, collect data from the environment and exchange data. Such toys have the ability to feel the environment, adapt to it and be remotely controlled. However, there is not enough bibliography on the development and use of toys in this category, but it is expected to flourish in the coming years.

\subsection{Educational Affordances}

Educational affordances are related on one hand to the educational context, i.e., the types of activity they allow and on the other hand the learning objectives at which smart toys aim.

\subsection{Types of Activity}

These affordances refer to the possible types of activities that can be developed inside or outside school. In particular, they relate to whether the game can be used in organized educational activities at school and/or can be used by the child in non-organized activities both inside and outside school.

An Organized Educational Activity (OEA) is structured game/activity that is integrated in a direct and predetermined way and is part of a wider framework of developmental activities organized by the teacher. The teacher is involved in the children's game, in order to guide, reinforce and deepen them and then connect previous experiences or create new ones, which are interconnected with the specific goals of a structured activity or a developmental activity plan.

In Free Game (FG) activities, children have the freedom to choose what kind of play/activity they want to do, what objects to choose, with whom and for as long as they want within the rules of class and the schedule in or outside school, at home or elsewhere.

The purpose is for children to come in contact with various objects/toys, use them according to their level of abilities, create scenarios, socialize, reflect, undertake roles, improvise, have fun, learn, explore, experiment and through these activities comprehensively evolve.

\subsection{Learning Objectives}

These skills relate to the play's specific or general learning objectives. The specific objectives refer to a learning subject, for example mathematical concepts, physics concepts and robotics concepts. The general objectives relate to transversal competencies, such as problem solving and collaboration. The concept of competence is defined as the extensive set of knowledge, skills, attitudes and values that the student has in his cognitive, mental 
and value potential, which he activates and uses as the case may be in order to successfully conduct specific activities. Transversal competencies are now a widespread way of growing curricula and are often referred to as 21st century skills. Such skills include problem solving, computational thinking and critical thinking.

\section{Results}

In Table 2 (see Appendix A that provides full reference details at the same numerical order) we present a synopsis of smart toys under study. As it is shown it provides information over the name of its toy, year of its development, related scientific articles, the technological and educational affordances and the ages addressed to.

Table 2. Classification of Smart Toys.

\begin{tabular}{|c|c|c|c|c|c|c|c|}
\hline \multirow[b]{2}{*}{ No } & \multirow[b]{2}{*}{ Name of Toy } & \multirow[b]{2}{*}{ Year } & \multirow[b]{2}{*}{ Paper/Papers } & \multirow[b]{2}{*}{$\begin{array}{l}\text { Technological } \\
\text { Affordances }^{1}\end{array}$} & \multicolumn{2}{|c|}{ Educational Affordances } & \multirow[b]{2}{*}{ Age } \\
\hline & & & & & $\begin{array}{c}\text { Type of } \\
\text { Activity }{ }^{2}\end{array}$ & $\begin{array}{c}\text { Learning } \\
\text { Objectives }\end{array}$ & \\
\hline 1 & LEGO/Logo & 1991 & $\begin{array}{l}\text { Resnick and Ocko, 1991; Resnick, } \\
1993\end{array}$ & SE & OEA_FG & Problem Solving-Robotics & $8-12$ \\
\hline 2 & $\begin{array}{l}\text { Programmable } \\
\text { Bricks-Cricket }\end{array}$ & 1994 & $\begin{array}{l}\text { Martin, 1994; Resnick, Martin, } \\
\text { Sargent, and Silverman, } 1996\end{array}$ & SE & OEA_FG & Problem Solving-Robotics & - \\
\hline 3 & Rosebud & 1997 & Glos and Cassell, 1997 & TF_SE & OEA_FG & Digital storytelling & - \\
\hline 4 & StoryMat & 1999 & Ryokai and Cassel, 1999 & TF_SE & OEA_FG & Digital storytelling & $4-8$ \\
\hline 5 & Curlybot & 2000 & Frei et al., 2000 & SE & OEA & Programming & $4-6$ \\
\hline 6 & $\begin{array}{c}\text { Smart } \\
\text { Kindergarten }\end{array}$ & 2001 & Srivastava, Muntz, Potkonjak, 2001 & SE & OEA_FG & $\begin{array}{l}\text { Various Concepts and } \\
\text { Activities }\end{array}$ & $4-6$ \\
\hline 7 & Dolltalk & 2002 & Vaucelle and Jehan, 2002 & TF_SE & FG & Digital storytelling & $4-8$ \\
\hline 8 & I/O Brush & 2004 & Ryokai et al., 2004 & $\mathrm{TF}$ & OEA_FG & Arts Education & $4-6$ \\
\hline 10 & $\begin{array}{l}\text { Augmented } \\
\text { Knight's Castle }\end{array}$ & 2007 & Lampe and Hinske, 2007 & AR_SE & FG & Digital storytelling & - \\
\hline 11 & Siftables & 2007 & Merill et al., 2007 & TF_SE & OEA_FG & $\begin{array}{l}\text { Various Concepts and } \\
\text { Activities }\end{array}$ & - \\
\hline 12 & TagTiles & 2007 & Verhaegh et al., 2007 & TF_SE & FG & $\begin{array}{l}\text { Various Concepts and } \\
\text { Activities }\end{array}$ & $8-12$ \\
\hline 13 & PageCraft & 2007 & Budd et al., 2007 & $\mathrm{TF}$ & OEA & Digital storytelling & - \\
\hline 14 & ARELS & 2008 & Hsieh and Lee., 2008 & $\mathrm{AR}$ & OEA & English & - \\
\hline 15 & SMART & 2008 & Freitas and Campos, 2008 & $\mathrm{AR}$ & OEA_FG & $\begin{array}{l}\text { Various Concepts and } \\
\text { Activities }\end{array}$ & $7-8$ \\
\hline 16 & DigiTile & 2009 & Rick et al., 2009 & SE & OEA_FG & $\begin{array}{l}\text { Various Concepts and } \\
\text { Activities }\end{array}$ & $8-12$ \\
\hline 17 & Arduino Etoys & 2010 & Zabala et al., 2010 & SE & OEA & Physics & - \\
\hline 18 & LilyPad Arduino & 2010 & Y. B. Kafai et al., 2010 & $\mathrm{TF}$ & FG & STEM & - \\
\hline 19 & Crafti & 2011 & Castañer et al., 2011 & $\mathrm{AR}$ & OEA_FG & $\begin{array}{l}\text { Various Concepts and } \\
\text { Activities }\end{array}$ & $6-12$ \\
\hline 20 & TinkRBook & 2011 & Chang and Breaseal, 2011 & $\mathrm{TF}$ & FG & Digital storytelling & $3-6$ \\
\hline 21 & Towards Utopia & 2011 & A. N. Antle et al., 2011 & $\mathrm{TF}$ & OEA & Fine motor skills & $8-12$ \\
\hline 22 & i-Cube & 2012 & W. B. Goh et al., 2012 & $\mathrm{TF}$ & OEA & $\begin{array}{l}\text { Interactivity/Spatial } \\
\text { Thinking }\end{array}$ & $4-6$ \\
\hline 23 & Tangicons 3.0 & 2012 & F. Scharf et al., 2012 & $\mathrm{TF}$ & OEA & Problem Solving-Robotics & $7-8$ \\
\hline 24 & StoryTech & 2013 & $\begin{array}{c}\text { Kara et al., 2013; Kara and Cagiltay, } \\
2020\end{array}$ & $\mathrm{AR}$ & FG & Digital storytelling & $3-6$ \\
\hline 25 & AIBLE & 2014 & Fleck et al., 2014 & $\mathrm{AR}$ & OEA & Physics & $8-12$ \\
\hline 26 & $\begin{array}{l}\text { Sketch-Play- } \\
\text { Learn }\end{array}$ & 2015 & Agarwal and Tripat, 2015 & $\mathrm{AR}$ & OEA & Physics & $8-12$ \\
\hline 27 & TangiSense & 2015 & Kubicki et al., 2015 & TF_SE & OEA_FG & Arts Education & $3-6$ \\
\hline 28 & TOK & 2015 & Sylla et al., 2015 & TF_SE & FG & Digital storytelling & $4-8$ \\
\hline 29 & KIBO robot & 2015 & A. Sullivan et al., 2015 & $\mathrm{TF}$ & OEA & STEM & $4-8$ \\
\hline 30 & ColAR mix & 2015 & Y. Huang et al., 2015 & $\mathrm{AR}$ & OEA & Arts Education & $4-6$ \\
\hline 31 & Code Bits & 2016 & Goyal, Vijay, Monga, Kalita, 2016 & AR_TF & OEA & Programming & $4-12$ \\
\hline 32 & EMT & 2016 & Yilmaz, 2016 & $\mathrm{AR}$ & OEA_FG & $\begin{array}{l}\text { Various Concepts and } \\
\text { Activities }\end{array}$ & $4-6$ \\
\hline
\end{tabular}


Table 2. Cont

\begin{tabular}{|c|c|c|c|c|c|c|c|}
\hline \multirow[b]{2}{*}{ No } & \multirow[b]{2}{*}{ Name of Toy } & \multirow[b]{2}{*}{ Year } & \multirow[b]{2}{*}{ Paper/Papers } & \multirow{2}{*}{$\begin{array}{l}\text { Technological } \\
\text { Affordances }^{1}\end{array}$} & \multicolumn{2}{|c|}{ Educational Affordances } & \multirow[b]{2}{*}{ Age } \\
\hline & & & & & $\begin{array}{c}\text { Type of } \\
\text { Activity }^{2}\end{array}$ & $\begin{array}{c}\text { Learning } \\
\text { Objectives }\end{array}$ & \\
\hline 33 & Teddy bear & 2016 & $\begin{array}{l}\text { Goula -Dimitriou and Dasygenis, } \\
2016\end{array}$ & SE & FG & $\begin{array}{c}\text { Collaboration/Emotional } \\
\text { Thinking }\end{array}$ & $3-6$ \\
\hline 34 & Helios & 2016 & Fleck and Hacket, 2016 & AR_TF & OEA & Physics & $8-12$ \\
\hline 35 & Hobit & 2016 & Fleck and Hacket, 2016 & AR_TF & OEA & Physics & $8-12$ \\
\hline 36 & Teegi & 2016 & Fleck and Hacket, 2016 & AR_TF & OEA & Biology & $8-12$ \\
\hline 37 & TanProRobot 2.0 & 2016 & D. Wang et al., 2016 & $\mathrm{TF}$ & OEA & Programming & $4-12$ \\
\hline 38 & MagicBuns & 2016 & Huysduynen et al., 2016 & $\mathrm{TF}$ & OEA & $\begin{array}{l}\text { Interactivity/Spatial } \\
\text { Thinking }\end{array}$ & $4-6$ \\
\hline 39 & Futurocube & 2017 & J. Sander et al., 2017 & IOT & OEA & Programming & $7-8$ \\
\hline 40 & $\begin{array}{l}\text { Anki's Cosmo } \\
\text { robot }\end{array}$ & 2018 & S. Druga et al., 2018 & TF_SE & OEA & Computational Thinking & $4-12$ \\
\hline 41 & The bracelet & 2018 & B. Zaman et al., 2018 & IoT_TF & OEA_FG & STEM & - \\
\hline 42 & 3D Figurine & 2018 & B. Zaman et al., 2018 & IoT_TF & OEA_FG & STEM & - \\
\hline 43 & $\begin{array}{l}\text { Interactive board } \\
\text { game }\end{array}$ & 2018 & S. Mironcika et al., 2018 & $\mathrm{TF}$ & OEA_FG & Fine motor skills & $7-8$ \\
\hline 44 & CogniToys Dino & 2018 & Ihamäki and Heljakka, 2018 & IoT & FG & $\begin{array}{c}\text { Various Concepts and } \\
\text { Activities }\end{array}$ & $4-6$ \\
\hline 45 & $\begin{array}{c}\text { Wonder } \\
\text { Workshop's } \\
\text { Dash and Dash } \\
\text { Robot }\end{array}$ & 2018 & Ihamäki and Heljakka, 2018 & IoT_TF & FG & Problem Solving—Robotics & $4-6$ \\
\hline 46 & $\begin{array}{l}\text { Fisher-Price's } \\
\text { Smart Toy Bear }\end{array}$ & 2018 & Ihamäki and Heljakka, 2018 & IoT_TF & FG & $\begin{array}{l}\text { Interactivity/Spatial } \\
\text { Thinking }\end{array}$ & $4-6$ \\
\hline 47 & FingAR & 2019 & J. Hong et al., 2019 & $\mathrm{AR}$ & OEA & Symbolic thinking & $3-6$ \\
\hline 48 & $\begin{array}{l}\text { Osmo Genius } \\
\text { KIT Tangram }\end{array}$ & 2019 & Chan, 2019 & $\mathrm{TF}$ & OEA_FG & Fine motor skills & $6-12$ \\
\hline 49 & Tamagotchi & 2019 & Berriman and Mascheroni, 2019 & TF_SE & FG & $\begin{array}{c}\text { Collaboration/Emotional } \\
\text { Thinking }\end{array}$ & \\
\hline 50 & CRISPEE KIT & 2020 & Strawhacker et al., 2020 & $\mathrm{TF}$ & OEA_FG & Biology & $4-8$ \\
\hline 51 & mBot Arduino & 2020 & S.-Y. Lin et al., 2020 & $\mathrm{TF}$ & OEA & Computational Thinking & $4-6$ \\
\hline 52 & Hello Barbie & 2020 & Mertala, 2020 & TF_SE & FG & Symbolic thinking & \\
\hline
\end{tabular}

In Figure 2 it is shown the distribution of smart toys per year. As it is notable there is an increasing number of smart toys developed over the last five years and especially in 2015, 2016 and 2018, whereas only a small number (8/52) is recorded in the first 15 years.

\section{Toys / year}

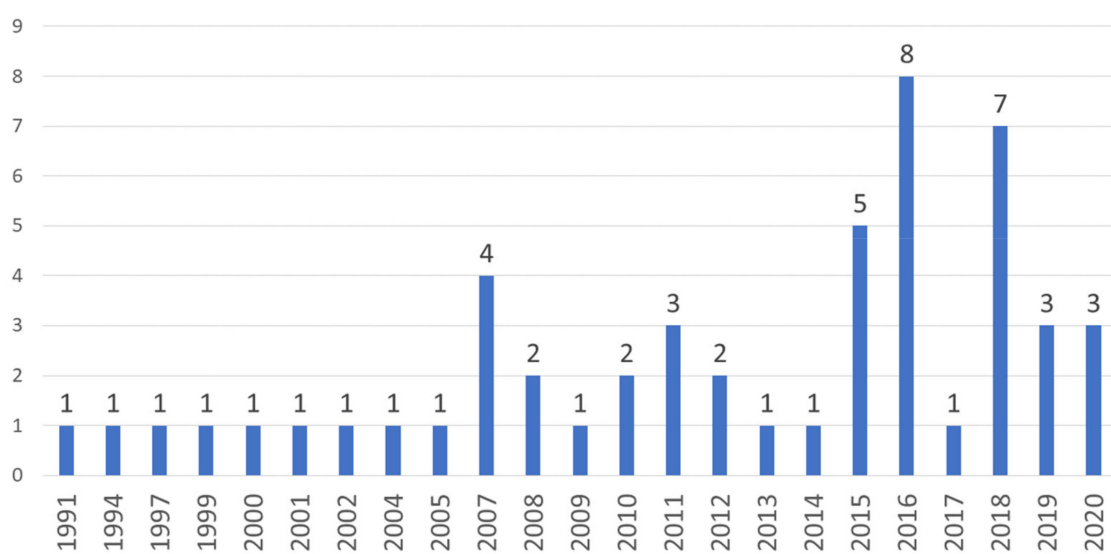

Figure 2. Number of toys per year. 
According to the data under study, smart toys seem to cover a significant wide range of age distribution which refers from 3 to 12 years old (Figure 3). Especially for 13 of 52 smart toys, no data is mentioned regarding the target age group, though their developers suggest them for children in primary education. Another significant number of smart toys (16/52), as presented in Figure 3, is addressed to the age groups of 3-6 and 4-6, whereas only 10 of the total are targeting older children like 8-12 years old. Finally, we can see that $13 / 25$ smart toys present a small distribution in different age groups distributed from 4 to 12 years old.

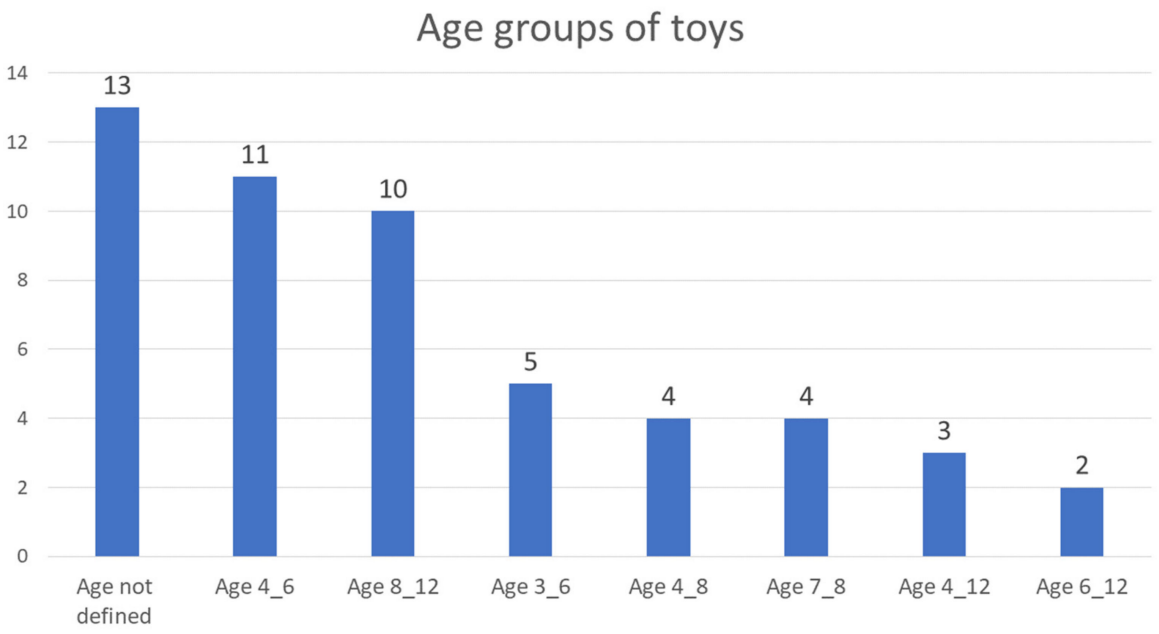

Figure 3. Age groups of toys.

The following two units describing in more detail the technological and educational affordances of smart toys.

\subsection{Technological Affordances of Smart Toys}

The present unit describes the categorisation of smart toys regarding their technological affordances and/or their combination of them. As it emerges, not only from the state of the art but mostly from the data under study, it is evident that research interest covers a broad range of scientific fields such as computer science, robotics, internet and specific areas of computing (user interfaces, interaction design). However, the AI technological development does not seem to have a significant effect in smart toys' deployment in children aged 3-12 years.

In Figure 4 the technological affordances of smart toys present in descending order.

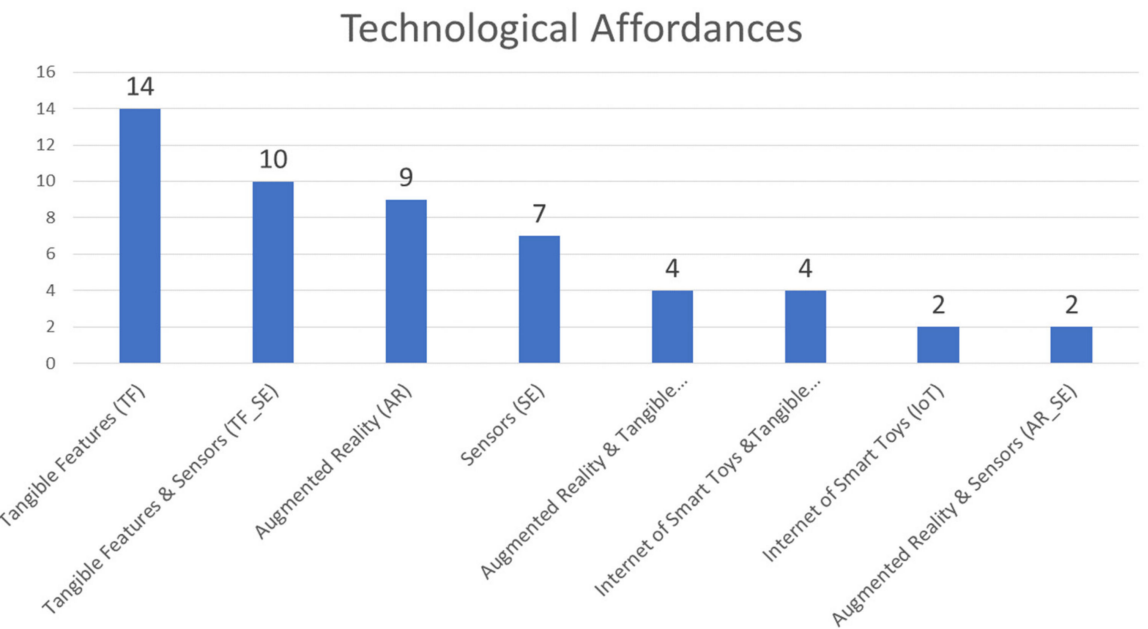

Figure 4. Technological affordances of smart toys. 


\subsubsection{Technological Affordances and Physical Activity}

The analysis shows that tangible features are present in most smart toys. Smart toys, including tangible features and sensors, are representing the 50\% $(24 / 52)$ of smart toys understudy, which if we add the case of smart toys including tangible features and other characteristics (Augmented Reality and Internet of Smart Toys) reaches the 60\% (32/52). The use of tangible features in smart toys especially addressing at young ages, can provide a concrete way to foster skills through "physical activity", thus combining a playful and meaningful way to learning. Likewise, we can suggest that tangible features and sensors may be regarded as the second major category $(17 / 25)$. The case here is that sensors contribute to enhancing the interaction between the user and the environment, which at the end requires "physical activity".

\subsubsection{Technological Affordances and "Mixed" Activity}

Overall, 15 smart toys understudy offer affordances of augmented reality, or in combination with other characteristics (Tangible features $k \alpha \iota$ Sensors). In that case, users are involved in activities which either need physical effort or digital process. In other words, a significant number of smart toys understudy provide users with activities combining not only physical but also digital deployment. We call it "mixed activity", and it is a main technological feature in those smart toys.

\subsection{Educational Affordances of Smart Toys}

The educational affordances imply different activities and are placed in or out of an educational environment. Therefore, our analysis includes several smart toys related to three types of activity: (a) organized educational activity, (b) free game and (c) combination of both. However, as suggested from our data, the type of organized educational activities is mostly presented (Figure 5).

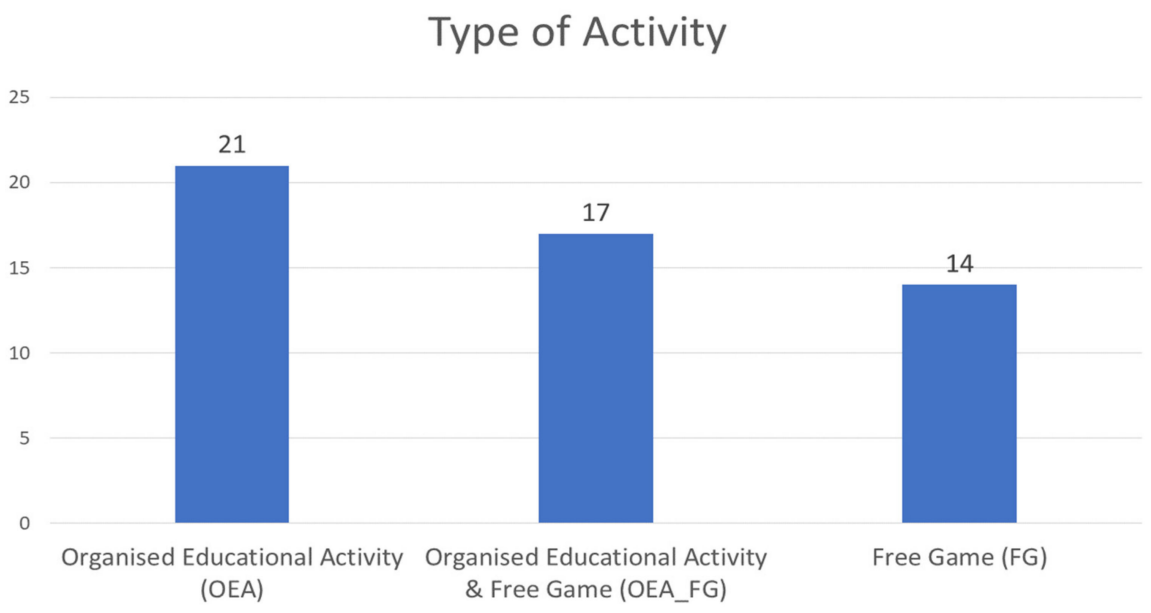

Figure 5. Types of activities and smart toys.

The following figure (Figure 6) shows the frequency of learning objectives addressed by the smart toys understudy. Notably, learning objectives consisting of two major categories: (a) those related to 21st century transversal competencies and (b) those related to specialized discipline. The primary learning objectives referred to as 21st-century competencies are problem solving with robots, computational thinking, symbolic thinking, collaboration and emotional thinking. Regarding skills' enhancement digital storytelling and various concepts and activities present higher frequency than those with lower frequency, such as collaboration and emotional thinking, fine motor skills, interactivity and spatial thinking, computational thinking and symbolic thinking. On the other hand, it is shown learning objectives related to certain disciplines such as: STEM, physics, math, programming, biology, art and English. 


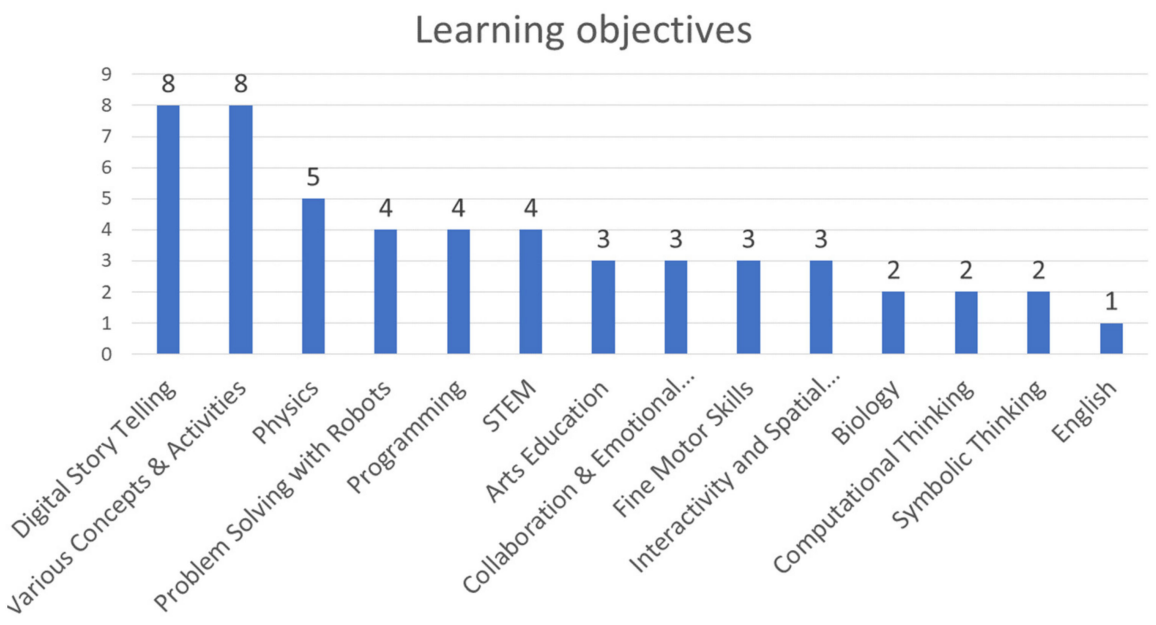

Figure 6. Learning objectives of smart toys.

As highlighted by analysing the learning objectives, some conclusions deserve further study. Firstly, a certain number of transversal competencies of the 21st century is likely to emerge due to particular affordances addressed by the smart toys understudy. Secondly, although learning objectives cover some basic disciplines like science, math, computing and arts, there are not deepening enough in learning. Mainly, learning objectives in science and math focus on specific curriculum areas rather than covering a broad range of teaching topics. Finally, digital storytelling seems to be mostly the medium for teaching English and expressive arts.

\section{Discussion}

To explore the global structure of our data (Table 2), we have applied the multivariate analysis method of Multiple Correspondence Analysis [71,72]. The multivariate methods constitute tools appropriate to investigate relationships between variables, especially when research data concern simultaneous measurements of various parameters [73]. These methods integrate possibilities like data reduction, sorting and grouping variables, to investigate similarities and dissimilarities between groups, investigate the dependence and/or interdependence relations among variables, and predict relationships between variables. Multiple Correspondence Analysis (MCA) is a well-established multivariate method that allows us to analyse and describe our research data graphically and synthetically. It offers effective tools that can help us to overcome the intrinsic limitations of the descriptive statistics presented in the previous sections. It aims at the graphical representation of the structure of categorical (non-numerical) multivariate data. The main principle of this method is that complex multivariate data can be accessible by displaying its main regularities and patterns in graphs and diagrams. We have chosen this type of analysis because it can help us reveal the various correlations between the different variables that describe our data and consequently study smart toys' affordances more thoroughly.

The smart toys under study are described by a number of variables: year, technological affordances, types of activity, learning objectives and target age. Unfortunately, the fine structure of relations between these smart toys cannot be revealed through descriptive statistical methods. However, with the help of the MCA method, we can derive how their different characteristics (affordances) correlate across the year of development and the target age group. Furthermore, we can construct a topographic map of those parameters, making smart toys' classification easily presentable based on their technological and educational affordances.

We employed our analysis using the software SPAD version 7.4 (SPAD, 2000). We applied the CORMU (Correspondences Multiples) method, which is equivalent to the HOMALS (Homogeneity Analysis) procedure of SPSS version 11 (SPSS, 2002). As active (dependent) variables, we have used the Technological Affordances, the Type of Activity and 
the Learning Objectives. The Year and the Age were used as supplementary (independent) variables.

The variable Technological Affordances includes eight (8) categories or modalities (Figure 4): Tangible Features (TF), Augmented Reality Features (AR), Internet of Things Features (IoT), Sensor equipped Features (SE), Tangible Features and Sensors (TF_SE), Augmented Reality and Sensors (AR_SE), Augmented Reality and Tangible Features (AR_TF) and Internet of Things and Tangible Features (IoT_TF).

Two variables describe the Educational Affordances: "Type of Activity" with three (3) categories or modalities (Organized Educational Activity (OEA), Free Game (FG) and OEA_FG) and "Learning Objectives" with 14 categories or modalities (Arts Education, Biology, Collaboration and Emotional Thinking, Computational Thinking, Storytelling, English, Fine Motor Skills, Interactivity and Spatial Thinking, Physics, Problem Solving with Robots, Programming, STEM, Symbolic Thinking, Various Concepts and Activities).

Applying the MCA, we can derive several factors, which determine all the information produced. Each factor is described by two parameters [71]: The eigenvalue $\lambda$, which corresponds to the eigenvectors characterizing the values of the variables implicated in the analysis and the coefficient of inertia $\tau$, which is the proportion of the total information in the factor, as the MCA analysis provides it.

We can classify MCA factors in descending order according to their importance, as far as the full information is provided. Table 3 presents the eigenvalues and the coefficients of inertia for the first five factors revealed by our analysis. As we can see, they cumulatively represent the inertia at a percentage of $41.86 \%$, which corresponds to $41.86 \%$ of the total information produced. In our study, we analyse extensively only the first and second factors, which offer $19.57 \%$ of the total information but provide a reasonable interpretation 16 of the 25 modalities of study.

Table 3. MCA Parameters' Values.

\begin{tabular}{cccc}
\hline Factor & Eigenvalue & Percentage & Cumulated Percentage \\
\hline 1 & 0.7539 & 10.77 & 10.77 \\
2 & 0.6160 & 8.80 & 19.57 \\
3 & 0.5755 & 8.22 & 27.79 \\
4 & 0.5247 & 7.50 & 35.29 \\
5 & 0.4603 & 6.58 & 41.86 \\
\hline
\end{tabular}

The first axis (factor) has eigenvalue $\lambda 1=0.7539$ and coefficient of inertia $\tau 1=10.77 \%$. This is essentially characterized as the factor of Educational Affordances (Table 4). It is a very important factor in our analysis, since it shows the opposition between:

(a) Organized Educational Activities vs Free Game activities.

(b) Specific curriculum Learning Objectives (Programming and Physics) vs. 21 century competencies (Collaboration, Emotional Thinking, Storytelling).

(c) Differences between Augmented Reality based smart toys (Augmented Reality with Sensors vs Augmented Reality with Tangible features).

Table 4. Printout on factor 1 by the active variables.

\begin{tabular}{cccc}
\hline Variable Label & Category Label & Test-Value & Weight \\
\hline Type of Educational Activity & FG & -4.96 & 14,000 \\
Technological Affordance & TF_SE & -3.36 & 10,000 \\
Learning Objectives & CollabEmotThinking & -3.01 & 3000 \\
Learning Objectives & StoryTelling & -3.01 & 8000 \\
Technological Affordance & AR_SE & -2.82 & 2000 \\
M I D D L E A R E A & Programming & 2.62 & 4000 \\
Learning Objectives & Physics & 3.42 & 5000 \\
Learning Objectives & AR_TF & 3.82 & 4000 \\
Technological Affordance & OEA & 5.83 & 21,000 \\
Type of Educational Activity & & & \\
\hline
\end{tabular}


The second axis (factor), with eigenvalue $\lambda 2=0.6160$ and coefficient of inertia $\tau 2=8.8 \%$ is essentially characterized as the factor of 21st century competencies and various technological affordances (Table 5). It shows the opposition between:

(a) Problem Solving, STEM and various curriculum Activities vs Collaboration, Emotional Thinking and Story Telling

(b) Free Game Activities vs Organized Educational Activities and Free Game Activities

(c) Augmented Reality with Sensors and Augmented Reality with Tangible features vs Internet of Smart Toys with Tangible features.

Table 5. Printout on factor 2 by the active variables.

\begin{tabular}{cccc}
\hline Variable Label & Category Label & Test-Value & Weight \\
\hline Technological Affordance & AR_SE & -3.14 & 2000 \\
Type of Educational Activity & FG & -3.02 & 14,000 \\
Learning Objectives & CollabEmotThinking & -2.89 & 3000 \\
Technological Affordance & AR_TF & -2.52 & 4000 \\
Type of Educational Activity & OEA & -2.26 & 21,000 \\
Learning Objectives & StoryTelling & -2.14 & 8000 \\
M I D D L E A R E A & VariousActivities & 2.16 & 8000 \\
Learning Objectives & ProblemSolvingRobot & 2.27 & 4000 \\
Learning Objectives & STEM & 2.65 & 4000 \\
Learning Objectives & OEA_FG & 5.21 & 17,000 \\
Type of Educational Activity & & \\
\hline
\end{tabular}

In more detail, Figure 7 shows the graphical representation of our results in a factor plan created by the first two and more important axes. Smart toys' technological and educational affordances are represented in the graph represented by their values (categories). When projected on the factor plan, the values of the three active variables (Technological affordances, Type of activity and Learning objectives) define three clouds or groups of categories. Each group includes categories of variables that represent the group's typical characteristics of smart toys.

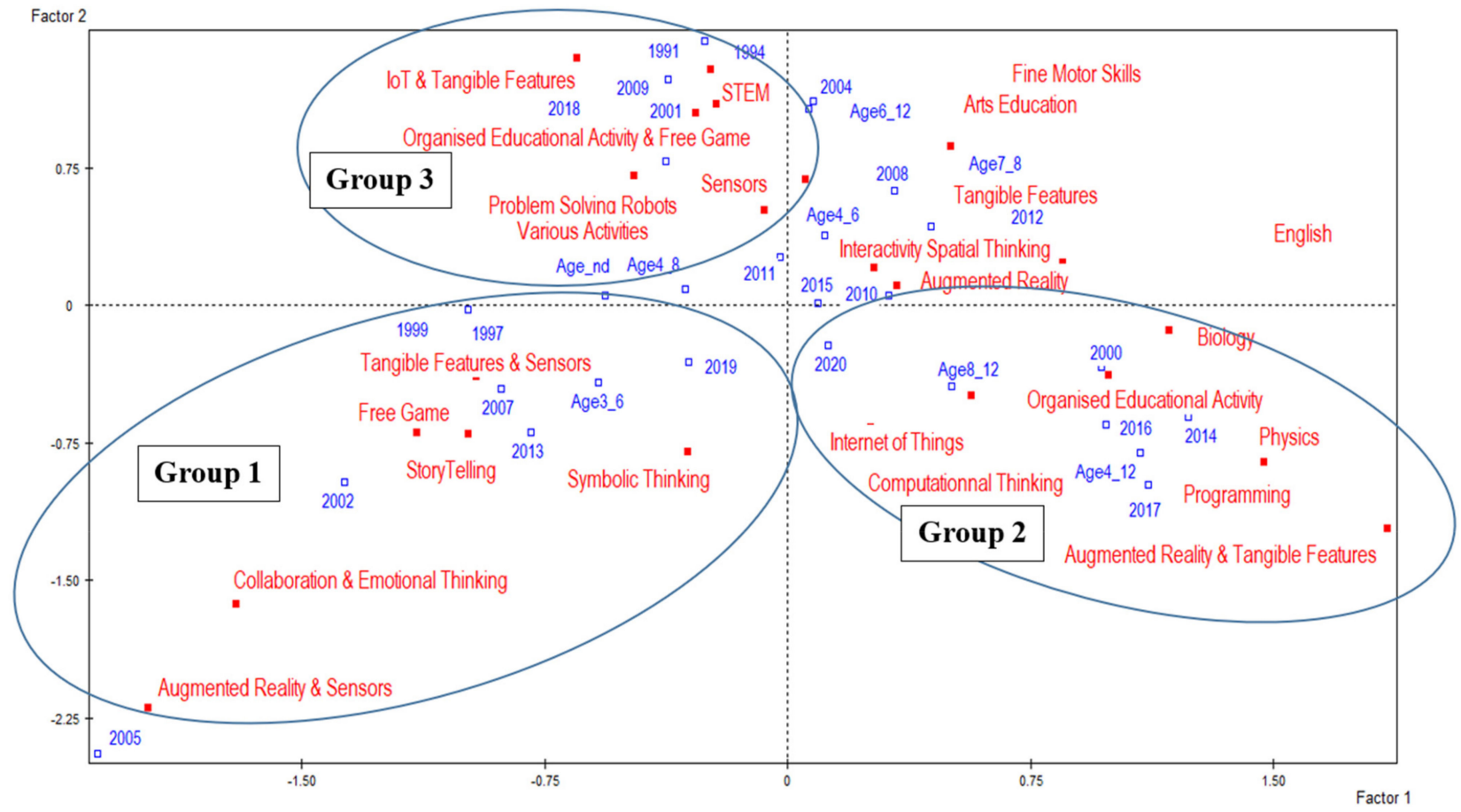

Figure 7. Factorial Plan (Factor/Axis 1 X Factor/Axis 2). 
The first cloud (Group 1) is defined by the values FG (Variable: Type of Activity), TF_SE, AR_SE (Variable: Technological Affordances), CollabEmotThinking, StoryTelling (Variable: Learning Objectives). Augmented Reality with Sensors, Smart toys with Tangible features and Sensors, Free Game activities and certain 21st-century competencies (Collaboration, Emotional Thinking, Story Telling and Symbolic Thinking) are the categories that this Group contains. These are the key affordances of the smart toys of this Group. As shown in Figure 7, a group of smart toys developed in 1999, 2002, 2005, 2007 and 2013 (principally during the middle chronological period regarding our study of smart toys) and their age target group applies to 3-6 years old.

The second cloud (Group 2) is determined by the values corresponding to the Organized Educational Activities, the specific curriculum Learning Objectives (Physics, Biology, Programming), the Internet of Things smart toys, and Augmented Reality toys with Tangible Features. As we can see in Figure 7, a group of smart toys developed in 2000, 2014, 2016, 2017 and 2020 (essentially during the more recent chronological period regarding our study of smart toys). Their age target group comprises the 4-12 years and the 8-12 years.

The third cloud (Group 3) groups the Problem Solving with Robots, the STEM activities, the various curriculum Activities, the Organized Educational Activities, Free Game activities and the smart toys with the affordances of Internet of Things with Tangible Features and Sensors.

As shown in Figure 7, a group of smart toys developed in 1991, 1994 and 2004 (essentially during the first chronological period regarding our study of smart toys) as well as 2018, the year in which developed games for Internet of Things and Tangible Features. Their age target group applies to children $4-8$ years and the non-defined age.

\section{Conclusions}

The term Smart Toys has been established in bibliography and scientific research in recent decades. It characterises the research area that studies when a toy can be considered smart and deals with the development and use of this type of toys in educational or noneducational uses. These games are very diverse, both technologically and educationally. For the time being, there are no categorisations of smart toys in terms of their various features, at least in a systematic way. Individual categorisations may relate to the technologies they incorporate, depending on how children interact with them or the types of activities they support or the purpose they serve. A core categorisation of smart toys can be performed based on their ability to be used as educational or not toys and their learning area.

The present paper attempts a systematic review of non-commercial smart toys that have been developed in the last 30 years for the early childhood and primary education (from 3 to 12 years old). This review is organised following two complementary axes: smart toys' technological affordances and educational affordances. The review's objective is to answer two questions:

(a) How are smart toys categorized based on the technological (and other) elements they incorporate?

(b) How are smart toys categorized based on the educational framework where they have been developed and used?

Our study was based on an in-depth analysis of 50 research articles featuring 52 smart toys developed over 30 years. Although the number of smart toys that have been developed is much greater, we chose to study only those that have no commercial purpose and have been used to a degree or another for educational purposes but not in special needs education. Consequently, we have not analysed any toy for which even no empirical application had been made with children. The research area of smart toys has made significant progress in recent years. It largely relies on the technological development of various fields of Informatics and other sciences (Internet of Things, Robotics, user interfaces, tangible objects, etc.). Over the years, more and more smart toys seem to be developing. Most than half of the toys studied $(27 / 52)$ have been developed within the last six years. 
Smart toys focus on a variety of age target groups. Although there does not appear to be a particular tendency to focus on specific ages depending on the year of development, multiple correspondence analysis (MCA) shows that young age toys (3-6 or 4-8) appear as early as the first period of these smart toys occurs. In contrast, toys involving older ages (8-12) or toys with an extensive age range (4-12) have appeared mainly in recent years.

To answer the question of the categorisation of smart toys based on their technological affordances, we created a categorical variable (also called a qualitative variable) that regards these affordances. The data show four core values (categories) of this variable: (a1) Tangible Features (TF), (a2) Augmented Reality Features (AR), (a3) Internet of Things Features (IoT) and (a4) Sensor equipped Features (SE) as well as four values as combinations of the basic categories: (a5) Tangible Features and Sensors (TF_SE), (a6) Augmented Reality and Tangible Features (AR_TF), (a7) Augmented Reality and and Sensors (AR_SE) and (a8) Internet of Things Features and Tangible Features (IoT_TF). The main categories appear 32 times and their combinations appear 20 times. In addition, these categories are not randomly distributed in the period under examination. For the first twenty-five years, we have had toys with Tangible Features (14/52), Sensors (7/52), Augmented Reality (9/52) and a combination of them. However, only within the last five years, we have toys with IoT features (1/52) or a combination of IoT and Tangible Features (4/52), as well as Augmented Reality and Tangible Features (4/52). Finally, more than half of the smart toys developed combine two technological affordances over the last years. On the contrary, until 2015, less than $1 / 3$ of toys combine two technological affordances.

The question concerning the educational affordances of smart toys is studied in this article regarding two different aspects: (a) the types of possible activities that a student can perform with a toy and (b) the learning objectives that can be achieved while using a toy.

The categorical variable that studies the types of possible activities contains three categories: (b1) Organized Educational Activity (OEA), (b2) Free Game (FG) activity and (b3) their combination, i.e., Organized Educational Activity and Free Game (OEA and FG). Although, and especially in recent years, Organized Educational Activities have the highest frequency of occurrence (21/52), free game activities (14/52) or even combined activities (17/52) also occur several times, as is expected, given that the technological application used (smart toy), is by nature playful. As regards the evolution of the type of activities over time, the Multiple Correspondence Analysis shows that in the first period of development of smart toys (Figure 7, Group 3), the majority of games suggested mixed activities (Organized Educational Activity and Free Game), and particularly 9/18 for the years 1991-2010. The interim period (Figure 7, Group 1) focuses on Free Game activities (only 2 out of 14 games relate to the years before 2010), while the most recent period (Figure 7, Group 2), mainly concerns games suggested by Organized Educational Activities $(10 / 22$ for the last five years).

Interesting conclusions emerge from the analysis of the learning objectives of toys. The data coding gave rise to 14 categories for the categorical variable called "Learning Objectives". These categories are organized into two main axes: specific objectives related to specific cognitive objects and general objectives that refer to transversal skills and abilities of the 21st century. The specific objectives focus on specific sciences (physics, mathematics, programming, biology), arts and English. The general objectives cover some transversal skills (fine motor skills, storytelling, emotional thinking, symbolic thinking) and some 21st century skills (STEM, problem solving, collaboration, computational thinking). The analysis shows that not only the technological but the pedagogical affordances are also changing through the years. Especially, the Multiple Correspondence Analysis shows that in recent years smart toys concern special sciences (programming) and some 21st century skills (STEM and computational thinking), the first twenty years of development of smart toys, the interest is focused on transverse skills, such as Collaboration, Emotional Thinking, Symbolic Thinking, Story-Telling and Problem Solving.

This review is a first attempt in which we try to categorise the technological and educational aspects of smart toys since such categorisation cannot be found in the literature 
previously. Searching related studies of the past 30 years, we noticed that the term "smart" is related mainly one-dimensionally to the technological features that these toys integrate. However, in some studies the educational aspect is emphasised as equally important. The categorisation of smart toys based both on the technological features they incorporate and their educational affordances can lead to a unified framework of the definition of smart toys as formed over the last 30 years. What should be of great concern to us is the context of use of these toys. Questions of concern are whether a smart toy manages to support the child to have fun, and/or learn, and/or socialise, and/or interact with the environment around him/her in such a way that traditional toys cannot help him/her do it. Such a toy should support the performance of physical, sensory and perceptual activities that help children become aware of the world around them. In this direction, this review introduces the educational dimension in smart toys and explores how much it is considered in developing such prototype toys.

\section{Limitations and Perspectives}

Implication for practice and policy: Findings from this review indicate that researchers from technological fields may find it interesting to categorise technological features in smart toys as it may lead them to new developments or even a combination of existing features to shed light on the ergonomic uses of toys. Importantly, although we found that smart toys have been used in certain learning areas or for the evolution of certain skills, we found no evidence of integration into the curriculum or any particular learning approach, which would make policymakers think of the best ways to continue to provide high-performance outcomes by using them. Additionally, based on the affiliations of researchers-designers of smart toys, it appears that they mainly come from technological fields such as information technology and engineering, resulting in a particular perspective on the design and development of these toys. Given the impact of these toys on children and the skills they should have, their interests, and developmental needs, the involvement of experts from other fields, such as psychologists, educators or other professionals, is deemed necessary and inevitable.

Implication for research: Findings from this review suggest there is a strong body of research presenting smart toys' development and implementation in/or educational purposes. Though we did not study smart toys' cognitive and learning effectiveness since the research data available to us did not always focus on such questions, it is necessary to research in this direction. We also did not study the ergonomic uses of toys, which require special studies, which are not found in the bibliography. However, there are a couple of important questions worth further exploration and analysis. Our understanding of how children interact with these toys, or even further if the interaction is facilitated using these toys and how beneficial it might be in the learning process and the areas of learning would benefit from further implementation of the already mentioned toys in authentic learning contexts. Our understanding of how these toys can support the enhancement of children's cultural capital, especially in the early years of development, would benefit from high-quality studies that make direct comparisons among the different toys.

Author Contributions: Conceptualization, V.K., C.K. and A.J.; methodology, V.K., A.M., C.K., K.S. and D.M.; data collection, C.K., A.M., D.M. and K.S.; data analysis, C.K., D.M. and K.S.; statistical analysis, V.K.; resources, A.J.; data curation, V.K., A.J.; writing-original draft preparation, V.K., A.M., C.K., D.M. and K.S.; writing-review and editing, V.K., A.M., C.K. and A.J.; supervision, V.K.; project administration, V.K. All authors have read and agreed to the published version of the manuscript.

Funding: This research received no external funding.

Institutional Review Board Statement: Not applicable.

Informed Consent Statement: Not applicable.

Conflicts of Interest: The authors declare no conflict of interest. 


\section{Appendix A. List of Papers per Smart Toy}

1. Resnick, M.; Ocko, S. LEGO/Logo: Learning Through and About Design; Epistemology and Learning Group, MIT Media Laboratory: Cambridge, MA, USA, 1990; Volume 8, pp. 1-10.

2. Martin, F.G. Circuits to Control: Learning Engineering by Designing LEGO Robots. Ph.D. Thesis, Massachusetts Institute of Technology, Cambridge, MA, USA, 1994.

3. Resnick, M.; Martin, F.; Sargent, R.; Silverman, B. Programmable Bricks: Toys to think with. IBM Syst. J. 1996, 35, 443-452, doi:10.1147/sj.353.0443.

4. Glos, J.W.; Cassell, J. Rosebud: Technological toys for storytelling. In Proceedings of the CHI '97 Extended Abstracts on Human Factors in Computing Systems, Atlanta, GA, USA, 22-27 March 1997; pp. 359-360, doi:10.1145/1120212.1120433.

5. Resnick, M.; Martin, F.; Sargent, R.; Silverman, B. Programmable Bricks: Toys to think with. IBM Syst. J. 1996, 35, 443-452, doi:10.1147/sj.353.0443.

6. Frei, P.; Su, V.; Mikhak, B.; Ishii, H. Curlybot designing a new class of computational toys. In Proceedings of the SIGCHI Conference on Human Factors in Computing Systems, The Hague, The Netherlands, 1-6 April 2000; pp. 129-136.

7. Srivastava, M.; Muntz, R.; Potkonjak, M. Smart kindergarten: Sensor-based wireless networks for smart developmental problem-solving environments. In Proceedings of the Annual International Conference on Mobile Computing and Networking, MOBICOM, Rome, Italy, 16-21 July 2001; pp. 132-138.

8. Vaucelle, C.; Jehan, T. Dolltalk: A computational toy to enhance children's creativity. In Proceedings of the Extended abstracts of the 2002 Conference on Human Factors in Computing Systems, Minneapolis, MN, USA, 20-25 April 2002; CHI: 2002; pp. 776-777.

9. Ryokai, K.; Marti, S.; Ishii, H. I/O brush: Drawing with everyday objects as ink. In Proceedings of the 2004 Conference on Human Factors in Computing Systems, Vienna, Austria, 24-29 April 2004; CHI; ACM Press: New York, NY, USA, 2004; pp. 303-310.

10. Brederode, B.; Markopoulos, P.; Gielen, M.; Vermeeren, A.; de Ridder, H. pOwerball. In Proceedings of the 2005 Conference on Interaction Design and Children-IDC '05, Boulder, CO, USA, 8-10 June 2005; pp. 32-39.

11. Lampe, M.; Hinske, S. Integrating Interactive Learning Experiences into Augmented Toy Environments. Wortkshop on Pervasive Learning. 2007. pp. 1-9. Available online: https://pdfs.semanticscholar.org/2559/872b5d855a4c6153 8cc454a28dc4c8d76656.pdf (accessed on 5 August 2021).

12. Merrill, D.; Kalanithi, J.; Maes, P. Siftables. In Proceedings of the 1st International Conference on Tangible and embedded interaction-TEI '07, Baton Rouge, LA, USA, 15-17 February 2007; pp. 75-78.

13. Verhaegh, J.; Fontijn, W.; Hoonhout, J. TagTiles. In Proceedings of the 1st International Conference on Medical and Health Informatics, Taichung City, Taiwan, 20-22 May 2017; p. 187.

14. Budd, J.; Madej, K.; Stephens-Wells, J.; de Jong, J.; Katzur, E.; Mulligan, L. PageCraft. In Proceedings of the 6th International Conference on Interaction Design and Children-IDC '07, Aalborg, Denmark, 6-8 June 2007; pp. 97-100.

15. Hsieh, M.; Lee, J. AR Marker Capacity Increasing for Kindergarten English Learning. Lecture Notes Eng. Comput. Sci. 2008, 2168, 663-666.

16. Freitas, R.; Campos, P. SMART: A SysteM of Augmented Reality for Teaching 2nd Grade Students. People Comput. XXII Cult. Creat. Interact. 2008, 22, 27-30, doi:10.14236/ewic/hci2008.26.

17. Rick, J.; Rogers, Y.; Haig, C.; Yuill, N. Learning by doing with shareable interfaces. Child. Youth Environ. 2009, 19, 321-342.

18. Zabala, G.; Moran, R.; Blanco, S. Arduino Etoys A programming platform for Arduino on Physical Etoys. In Proceedings of the 1st International Conference on Robotics in Education, 2010; pp. 113-117. Available online: http://caeti.uai.edu.ar/archivos/276_ARDUINO_ETOYS_-A_PROGRAMMING_PLATFORM_FOR_ARDU INO_ON_PHYSICAL_ETOYS.PDF (accessed on 5 August 2021).

19. Kafai, Y.B.; Peppler, K.A.; Burke, Q.; Moore, M.; Glosson, D. Fröbel's forgotten gift. In Proceedings of the 9th International Conference on E-Education, E-Business, E-Management and E-Learning-IC4E '18, San Diego, CA, USA, 11-13 January 2018; pp. 214-217.

20. Castañer, M.; Camerino, O.; Pares, N.; Landry, P. Fostering Body Movement in Children through an Exertion Interface as an Educational Tool. Procedia Soc. Behav. Sci. 2011, 28, 236-240, doi:10.1016/j.sbspro.2011.11.046.

21. Chang, A.; Breazeal, C. TinkRBook. In Proceedings of the 10th International Conference on Predictive Models in Software Engineering, Turin, Italy, 17 September 2014; pp. 145-148.

22. Antle, A.N.; Wise, A.F.; Nielsen, K.; Canada, B.C. In Proceedings of IDC 2015: The 14th International Conference on Interaction Design and Children, Boston, MA, USA, 21-24 June 2015; pp. 11-20. 
23. Goh, W.B.; Kasun, L.L.C.; Fitriani; Tan, J.; Shou, W. The i-Cube. In Proceedings of the Designing Interactive Systems Conference on-DIS '12, Newcastle Upon Tyne, UK, 11-15 June 2012; pp. 398-407.

24. Scharf, F.; Winkler, T.; Hahn, C.; Wolters, C.; Herczeg, M. Tangicons 3.0: An Educational Non-Competitive Collaborative Game, In Proceedings of the 11th International Conference on Interaction Design and Children, Bremen, Germany, 12 June 2012

25. Kara, N.; Aydin, C.C.; Cagiltay, K. Investigating the activities of children toward a smart storytelling toy. Educ. Technol. Soc. 2013, 16, 28-43.

26. Kara, N.; Cagiltay, K. Smart toys for preschool children: A design and development research. Electron. Commer. Res. Appl. 2020, 39, 100909, doi:10.1016/j.elerap.2019.100909.

27. Fleck, S.; Simon, G.; Bastien, J.M.C. [Poster] AIBLE: An inquiry-based augmented reality environment for teaching astronomical phenomena. In Proceedings of the 2014 IEEE International Symposium on Mixed and Augmented Reality-Media, Art, Social Science, Humanities and Design (IMSAR-MASH'D), Germany, 10-12 September 2014; pp. 65-66.

28. Agarwal, B.; Tripathi, R. Sketch-Play-Learn-An Augmented Paper Based Environment for Learning the Concepts of Optics. In Proceedings of the 2015 ACM SIGCHI Conference on Creativity and Cognition, Glasgow, UK, 22-25 June 2015; pp. 213-216.

29. Kubicki, S.; Wolff, M.; Lepreux, S.; Kolski, C. RFID interactive tabletop application with tangible objects: Exploratory study to observe young children' behaviors. Pers. Ubiquitous Comput. 2015, 19, 1259-1274, doi:10.1007/s00779-015-0891-7.

30. Sylla, C.; Coutinho, C.; Branco, P.; Müller, W. Investigating the use of digital manipulatives for storytelling in pre-school. Int. J. Child-Comput. Interact. 2015, 6, 39-48, doi:10.1016/j.ijcci.2015.10.001.

31. Sullivan, A.; Elkin, M.; Bers, M.U. KIBO robot demo. In Proceedings of the 14th International Conference on Interaction Design and Children, Boston, MA, USA, 21-24 June 2015.

32. Huang, Y.; Li, H.; Fong, R. Using Augmented Reality in early art education: A case study in Hong Kong kindergarten. Early Child Dev. Care 2015, 186, 879-894, doi:10.1080/03004430.2015.1067888.

33. Goyal, S.; Vijay, R.S.; Monga, C.; Kalita, P. Code bits: An inexpensive tangible computational thinking toolkit for K-12 curriculum. In Proceedings of the TEI 2016-The 10th Anniversary Conference on Tangible Embedded and Embodied Interaction, Eindhoven, The Netherlands, 14-17 February 2016; pp. 441-447, doi:10.1145/2839462.2856541.

34. Yilmaz, R. Educational magic toys developed with augmented reality technology for early childhood education. Comput. Hum. Behav. 2016, 54, 240-248, doi:10.1016/j.chb.2015.07.040.

35. Goula-Dimitriou, M.; Dasygenis, M. Teddy bear upgraded with an embedded system to react on feelings. In Proceedings of the 2016 5th International Conference on Modern Circuits and Systems Technologies (MOCAST), Thessaloniki, Greece, 12-14 May 2016; 2016; pp. 1-4.

36. Fleck, S.; Hachet, M. Making Tangible the Intangible: Hybridization of the Real and the Virtual to Enhance Learning of Abstract Phenomena. Front. ICT 2016, 3, 30, doi:10.3389/fict.2016.00030.

37. Wang, D.; Zhang, L.; Xu, C.; Hu, H.; Qi, Y. A Tangible Embedded Programming System to Convey Event-Handling Concept. In Proceedings of the TEI '16: Tenth International Conference on Tangible, Embedded, and Embodied Interaction, Eindhoven, The Netherlands, 14-17 February 2016; pp. 133-140.

38. Van Huysduynen, H.H.; de Valk, L.; Bekker, T. Tangible Play Objects. In Proceedings of the Proceedings of the TEI '16: Tenth International Conference on Tangible, Embedded, and Embodied Interaction, Eindhoven, The Netherlands, 14-17 February 2016; pp. 262-270.

39. Sander, J.; De Schipper, A.; Brons, A.; Mironcika, S.; Toussaint, H.; Schouten, B.; Kröse, B. Detecting delays in motor skill development of children through data analysis of a smart play device. In Proceedings of the 11th EAI International Conference on Performance Evaluation Methodologies and Tools, Venice, Italy, 5-7 December 2017; pp. 88-91.

40. Druga, S.; Williams, R.; Park, H.W.; Breazeal, C. How smart are the smart toys? In Proceedings of the 17th ACM Conference on Interaction Design and Children, Trondheim, Norway, 19-22 June 2018; pp. 231-240.

41. Zaman, B.; Van Mechelen, M.; Bleumers, L. When toys come to life. In Proceedings of the 17th ACM Conference on Computer Supported Cooperative Work \& Social Computing, Baltimore, MD, USA, 15-19 February 2014; pp. 170-180.

42. Mironcika, S.; De Schipper, A.; Brons, A.; Toussaint, H.; Krose, B.; Schouten, B. Smart Toys Design Opportunities for Measuring Children's Fine Motor Skills Development. In Proceedings of the Twelfth International Conference on Tangible, Embedded, and Embodied Interaction, Stockholm, Sweden, 18-21 March 2018; pp. 349-356. 
43. Ihamäki, P.; Heljakka, K. Smart Toys for Game-based and Toy-based Learning. In Proceedings of the Eleventh International Conference on Advances in Human-Oriented and Personalized Mechanisms, Technologies, and Services, Nice, France, 14-18 October 2018; pp. 48-57.

44. Hong, J.; Ko, D.; Lee, W. Investigating the effect of digitally augmented toys on young children's social pretend play. Digit. Creat. 2019, 30, 161-176, doi:10.1080/14626268.2019.1653928.

45. Chan, K.K. Using Tangible Objects in Early Childhood Classrooms: A Study of Macau Pre-service Teachers. J. Fam. Econ. Issues 2020, 48, 441-450, doi:10.1007/s10643-019-01011-w.

46. Berriman, L.; Mascheroni, G. Exploring the affordances of smart toys and connected play in practice. New Media Soc. 2019, 21, 797-814, doi:10.1177/1461444818807119.

47. Strawhacker, A.; Verish, C.; Shaer, O.; Bers, M.U. Designing with Genes in Early Childhood: An exploratory user study of the tangible CRISPEE technology. Int. J. Child-Comput. Interact. 2020, 26, 100212, doi:10.1016/j.ijcci.2020.100212.

48. Lin, S.-Y.; Chien, S.-Y.; Hsiao, C.-L.; Hsia, C.-H.; Chao, K.-M. Enhancing Computational Thinking Capability of Preschool Children by Game-based Smart Toys. Electron. Commer. Res. Appl. 2020, 44, 101011, doi:10.1016/j.elerap. 2020.101011.

49. Mertala, P. How connectivity affects otherwise traditional toys? A functional analysis of Hello Barbie. Int. J. Child-Comput. Interact. 2020, 25, 100186, doi:10.1016/j.ijcci.2020.100186.

\section{References}

1. Lampe, M.; Hinske, S. Integrating Interactive Learning Experiences into Augmented Toy Envi-Ronments. 2007, pp. 1-9. Available online: https:/ / pdfs.semanticscholar.org/2559/872b5d855a4c61538cc454a28dc4c8d76656.pdf (accessed on 31 May 2021).

2. Levin, D.E.; Rosenquest, B. The Increasing Role of Electronic Toys in the Lives of Infants and Tod-Dlers: Should We Be Concerned? Contemp. Issues Early Child. 2001, 2, 242-247. [CrossRef]

3. National Association for the Education of Young Children and National Association of Early Childhood Specialists in State Departments of Education (NAEYC \& NAECS/ SDE) 1991. Guidelines for appropriate curricular content and assessment in programs for serving children ages 3 through 8. Young Child. 1991, 46, 21-38.

4. $\quad$ Fisher, K.; Hirsh-Pasek, K.; Golinkoff, R.M.; Singer, D.; Berk, L.E. Playing around in School: Impli-Cations for Learning and Educational Policy; Pellegrini, A., Ed.; Oxford University Press: New York, NY, USA, 2010; pp. 341-363.

5. Meckley, A. Observing Children's Play: Mindful Methods; Paper presented to the International Toy Research Association: London, UK, 2002.

6. Play. In Wikipedia. Available online: https://en.wikipedia.org/wiki/Play_(activity) (accessed on 5 March 2017).

7. Toy. In Wikipedia. Available online: https:/ / en.wikipedia.org/wiki/Toy (accessed on 5 March 2017).

8. Game. In Wikipedia. Available online: https:/ / en.wikipedia.org/wiki/Game (accessed on 9 March 2017).

9. Hourcade, J.P.; Revelle, G.; Zeising, A.; Iversen, O.S.; Pares, N.; Bekker, T.; Read, J.C. Child Computer Interaction SIG: New Challenges and Opportunities. pp. 1123-1126. Available online: https://www.researchgate.net/publication/302074038_Child-C omputer_Interaction_SIG_New_Challenges_and_Opportunities (accessed on 2 August 2021).

10. Read, J.C.; Bekker, M.M. The Nature of Child Computer Interaction; BCS Learning \& Development. 2011. Available online: https:/ / dl.acm.org/doi/10.5555/2305316.2305348 (accessed on 2 August 2021).

11. Resnick, M.; Martin, F.; Berg, R.; Borovoy, R.; Colella, V.; Kramer, K.; Silverman, B. Digital Manipulatives: New Toys to Think With. In Proceedings of the SIGCHI conference on Human factors in computing systems, Los Angeles, CA, USA, 18-23 April 1998; Volume 98, pp. 281-287.

12. Papert, S. Mindstorms, Children, Computers and Powerful Ideas; Basic Books: New York, USA, 1980.

13. Kara, N.; Cigdem Aydin, C.; Cagiltay, K. Investigating the Activities of Children toward a Smart Storytelling Toy. J. Educ. Technol. Soc. 2013, 16, 28-43.

14. Yilmaz, R.M. Educational Magic Toys Developed with Augmented Reality Technology for Early Child-Hood. Educ. Comput. Hum. Behav. 2016, 54, 240-248. [CrossRef]

15. Cagiltay, K.; Kara, N.; Aydin, C.C. Smart Toy Based Learning. In Handbook of Research on Educational Communications and Technology; Springer: New York, NY, USA, 2014; pp. 703-711.

16. Goldstein, J.; Buckingham, D.; Brougere, G. Introduction: Toys, Games, and Media; Routledge: Abingdon, UK, 2004 ; Chapter 1.

17. Shwe, H. Smarter Play for Smart Toys: The Benefits of Technology-Enhanced Play; Zowie Intertainment: San Mateo, CA, USA, 1999.

18. Srivastava, M.; Muntz, R.; Potkonjak, M. Smart Kindergarten: Sensor-Based Wireless Networks for Smart Developmental Problem-Solving Environments. 2001,pp. 132-138. Available online: https://www.researchgate.net/publication/2408354_Smart _Kindergarten_Sensor-Based_Wireless_Networks_for_Smart_Developmental_Problem-Solving_Environments (accessed on 2 August 2021).

19. Kara, N.; Aydin, C.C.; Cagiltay, K. Design and development of a smart storytelling toy. Interact. Learn. Environ. 2012, 22, 288-297. [CrossRef]

20. Johnson, J.E.; Christie, J.F. Play and Digital Media, Computers in the Schools: Interdisciplinary Journal of Practice. Theory Appl. Res. 2009, 26, 284-289. [CrossRef] 
21. Demir, S.; Şahin, F. Assessment of Prospective Science Teachers' Metacognition and Creativity Perceptions and Scientific Toys in Terms of Scientific Creativity. ERPA 2014. Procedia Soc. Behav. Sci. 2014, 152, 686-691. [CrossRef]

22. Glos, J.W.; Cassell, J. Rosebud: Technological Toys for Storytelling; Association for Computing Machinery: New York, NY, USA, 1997; pp. 359-360. [CrossRef]

23. Ryokai, K.; Cassell, J. Computer Support for Children's Collaborative Fantasy Play and Storytelling. In Proceedings of the 1999 Conference on Computer Support for Collaborative Learning-CSCL '99, Stanford, CA, USA, 12-15 December 1999; Association for Computational Linguistics: Morristown, NJ, USA, 1999.

24. Vaucelle, C.; Jehan, T. Dolltalk: A Computational Toy to Enhance Children's Creativity; Association for Computing Machinery: New York, NY, USA, 2002; pp. 776-777.

25. Sylla, C.; Coutinho, C.; Branco, P.; Müller, W. Investigating the Use of Digital Manipulatives for Storytelling in Pre-School. Int. J. Child Comput. Interact. 2015, 6, 39-48. [CrossRef]

26. Annany, M. Telling Tales: A New Way to Encourage Written Literacy through Oral Language. Master's Thesis, Media Arts and Sciences, Massachusetts Institute of Technology, Cambridge, MA, USA, 2001.

27. Raffle, H.; Vaucelle, C.; Wang, R.; Ishii, H. Jabberstamp: Embedding sound and voice in traditional drawings. In Proceedings of the 6th International Conference on Interaction Design and Children, Aalborg, Denmark, 6-8 June 2007; pp. 6-8.

28. Frei, P.; Su, V.; Mikhak, B.; Ishii, H. Curlybot Designing a New Class of Computational Toys. In Proceedings of the Conference on Human Factors in Computing Systems, New York, NY, USA, 1-6 April 2000; pp. 129-136. [CrossRef]

29. Merrill, D.; Kalanithi, J.; Maes, P. Siftables: Towards Sensor Network User Interfaces. In Proceedings of the TEI'07, First International Conference on Tangible and Embedded Interaction, Baton Rouge, LA, USA, 15-17 February 2007; pp. 75-78. [CrossRef]

30. Freitas, R.; Campos, P. SMART: A SysteM of Augmented Reality for Teaching 2nd Grade Students. 2008, Volume 22, pp. 27-30. Available online: https://www.researchgate.net/publication/221436730_SMART_A_SysteM_of_Augmented_Reality_for_Tea ching_2nd_Grade_Students (accessed on 2 August 2021).

31. Rick, J.; Rogers, Y.; Haig, C.; Yuill, N. Learning by Doing with Shareable Interfaces. Child. Youth Environ. 2009, 19, $321-342$.

32. Evans, M.A. Interactive Technologies for Embodied Learning of Language Arts \& Mathematics (ITEL*LAM): Developing Lesson Plans and Educational Applications for Elementary and Middle School Classrooms Using the IPod Touch. In Proceedings of the Association for Educational Communications and Technology International Conference, Louisville, KY, USA, 27 October 2009.

33. Fleck, S.; Simon, G.; Christian Bastien, J.M. [Poster] AIBLE: An Inquiry-Based Augmented Reality Environment for Teaching Astronomical Phenomena. In Proceedings of the 2014 IEEE International Symposium on Mixed and Augmented Reality-Media, Art, Social Science, Hu-manities and Design (IMSAR-MASH'D), Munich, Germany, 10-12 September 2014; IEEE: New York, NY, USA, 2014. [CrossRef]

34. Kerawalla, L.; Luckin, R.; Seljeflot, S.; Woolard, A. "Making It Real”: Exploring the Potential of Augmented Reality for Teaching Primary School Science. Virtual Reality 2006, 10, 163-174. [CrossRef]

35. Cascales, A.; Laguna, I.; Pérez-López, D.; Perona, P.; Contero, M. An Experience on Natural Sciences Augmented Reality Contents for Preschoolers; Springer: Berlin, Germany, 2013; Volume 8022, pp. 103-112.

36. Hsieh, M.; Lee, J. AR Marker Capacity Increasing for Kindergarten English Learning. Lecture Notes Eng. Comput. Sci. 2008, 2168, 663-666.

37. Agarwal, B.; Tripathi, R. Sketch-Play-Learn-An Augmented Paper Based Environment for Learning the Concepts of Optics. In Proceedings of the 2015 ACM SIGCHI Conference on Creativity and Cognition-C\&C '15, Glasgow, UK, 22-25 June 2015 ; ACM Press: New York, NY, USA, 2015. [CrossRef]

38. Ryokai, K.; Marti, S.; Ishii, H. I/O Brush: Drawing with Everyday Objects as Ink. In Proceedings of the 2004 Conference on Human Factors in Computing Systems, Vienna, Austria, 24-29 April 2004; pp. 303-310.

39. Campos, P.; Pessanha, S. Designing Augmented Reality Tangible Interfaces for Kindergarten Children. Lecture Notes Eng. Comput. Sci. 2011, 6773, 12-19.

40. Verhaegh, J.; Fontijn, W.; Hoonhout, J. TagTiles: Optimal Challenge in Educational Electronics. In Proceedings of the TEI'07: First International Conference on Tangible and Embedded Interaction, Baton Rouge, LA, USA, 15-17 February 2007; pp. 187-190. [CrossRef]

41. Zabala, G.; Moran, R.; Blanco, S. Arduino Etoys A Programming Platform for Arduino on Physical Etoys. In Proceedings of the 1st International Conference on Robotics in Education, Bratislava, Slovakia, 16-17 September 2010; pp. 113-117. Available online: http:/ / caeti.uai.edu.ar/archivos/276_ARDUINO_ETOYS_-A_PROGRAMMING_PLATFORM_FOR_ARDUINO_ON _PHYSICAL_ETOYS.PDF (accessed on 2 August 2021).

42. Kubicki, S.; Wolff, M.; Lepreux, S.; Kolski, C. RFID interactive tabletop application with tangible objects: Exploratory study to observe young children' behaviors. Pers. Ubiquitous Comput. 2015, 19, 1259-1274. [CrossRef]

43. Brederode, B.; Markopoulos, P.; Gielen, M.; Vermeeren, A.; de Ridder, H. pOwerball. In Proceedings of the 2005 Conference on Interaction Design and Children-IDC '05, Boulder, CO, USA, 8-10 June 2005; pp. 32-39.

44. Lin, S.-Y.; Chien, S.-Y.; Hsiao, C.-L.; Hsia, C.-H.; Chao, K.-M. Enhancing Computational Thinking Capability of Preschool Children by Game-based Smart Toys. Electron. Commer. Res. Appl. 2020, 44, 101011. [CrossRef]

45. Pan, Z.; López, M.F.; Li, C.; Liu, M. Introducing augmented reality in early childhood literacy learning. Res. Learn. Technol. 2021, 29, 29. [CrossRef] 
46. Fleck, S.; Hachet, M. Making Tangible the Intangible: Hybridization of the Real and the Virtual to Enhance Learning of Abstract Phenomena. Front. ICT 2016, 3, 30. [CrossRef]

47. Resnick, M. Technologies for lifelong kindergarten. Educ. Technol. Res. Dev. 1998, 46, 43-55. [CrossRef]

48. Resnick, M.; Ocko, S. LEGO/Logo: Learning through and about Design; E\&L Memo: Cambridge, MA, USA, $1991 ;$ pp. 1-10.

49. Resnick, M. Behavior construction kits. Commun. ACM 1993, 36, 64-71. [CrossRef]

50. Martin, F. Circuits to Control: Learning Engineering by Designing LEGO Robots. Ph.D. Thesis, MIT Media Laboratory, Cambridge, MA, USA, 1994.

51. Resnick, M.; Martin, F.; Sargent, R.; Silverman, B. Programmable Bricks: Toys to think with. IBM Syst. J. 1996, 35, 443-452. [CrossRef]

52. Goyal, S.; Vijay, R.S.; Monga, C.; Kalita, P. Code Bits: An Inexpensive Tangible Computational Thinking Toolkit for K-12 Curriculum. In Proceedings of the TEI 2016-The 10th Anniversary Conference on Tangible Embedded and Embodied Interaction, Eindhoven, The Netherlands, 14-17 February 2016; pp. 441-447. [CrossRef]

53. Horn, M.S.; Crouser, R.J.; Bers, M.U. Tangible interaction and learning: The case for a hybrid approach. Pers. Ubiquitous Comput. 2011, 16, 379-389. [CrossRef]

54. Castañer, M.; Camerino, O.; Pares, N.; Landry, P. Fostering Body Movement in Children through an Exertion Interface as an Educational Tool. Procedia Soc. Behav. Sci. 2011, 28, 236-240. [CrossRef]

55. Goula-Dimitriou, M.; Dasygenis, M. Teddy bear upgraded with an embedded system to react on feelings. In Proceedings of the 2016 5th International Conference on Modern Circuits and Systems Technologies (MOCAST), Thessaloniki, Greece, 12-14 May 2016; Institute of Electrical and Electronics Engineers (IEEE): New York, NY, USA, 2016; pp. 1-4.

56. Ganesan, M.; Russell, N.W.; Rajanand, R.; Welch, N.; Westeyn, T.L.; Abowd, G.D. Grip Sensing in Smart Toys: A Formative Design Method for User Categorization. In Proceedings of the CHI '10: CHI Conference on Human Factors in Computing Systems, Atlanta, GA, USA, 10-15 April 2010; Association for Computing Machinery: New York, NY, USA, 2010.

57. Westeyn, T.L.; Kientz, J.A.; Starner, T.E.; Abowd, G.D. Designing toys with automatic play characterization for supporting the assessment of a child's development. In Proceedings of the 7th International Conference on Pervasive Technologies Related to Assistive Environments, Crete, Greece, 25-27 May 2011; pp. 89-92.

58. Kitchenham, B. Procedures for Performing Systematic Reviews; Keele University Technical Report; Keele University: Newcastle, UK, 2004; pp. 1-26.

59. Page, M.J.; Moher, D.; Bossuyt, P.M.; Boutron, I.; Hoffmann, T.C.; Mulrow, C.D.; Shamseer, L.; Tetzlaff, J.M.; Akl, E.A.; Brennan, S.E.; et al. PRISMA 2020 explanation and elaboration: Updated guidance and exemplars for reporting systematic reviews. BMJ 2021, 372, n160. [CrossRef]

60. Norman, D.A. Affordance, Conventions, and Design. Interactions 1999, 6, 38-43. [CrossRef]

61. Salomon, G. (Ed.) Distributed Cognitions: Psychological and Educational Considerations; Cambridge University Press: New York, NY, USA, 1993.

62. Gibson, J.J. The Theory of Affordances; Shaw, R., Bransford, J., Eds.; Lawrence Erlbaum: Hillsdale, NJ, USA, 1977.

63. Ishii, H.; Ullmer, B. Tangible Bits: Towards Seamless Interfaces between People, Bits, and Atoms; ACM Press: New York, NY, USA, 1997; pp. 234-241.

64. O'Malley, C.; Fraser, D.S. Literature Review in Learning with Tangible Technologies. 2004. Available online: https://www.resear chgate.net/publication/32231466_Literature_Review_in_Learning_with_Tangible_Technologies (accessed on 2 August 2021).

65. Price, S.; Rogers, Y.; Scaife, M.; Stanton, D.; Neale, H. Using ‘Tangibles’ to Promote Novel Forms of Playful Learning. Interact. Comput. 2003, 15, 169-185. [CrossRef]

66. Do-Lenh, S.; Jermann, P.; Cuendet, S.; Zufferey, G.; Dillenbourg, P. Task Performance vs. Learning Out-Comes: A Study of a Tangible User Interface in the Classroom; Wolpers, M., Kirschner, P., Scheffel, M., Lind-Staedt, S., Dimitrova, V., Eds.; Springer: Berlin, Germany, 2010; Volume 6383, pp. 78-92.

67. Shaer, O. Tangible User Interfaces: Past, Present, and Future Directions. Found. Trends Human Comput. Interact. 2009, 3, 1-137. [CrossRef]

68. Huang, Y.; Li, H.; Fong, R. Using Augmented Reality in early art education: A case study in Hong Kong kindergarten. Early Child Dev. Care 2015, 186, 879-894. [CrossRef]

69. Boss, S.; Bruce, H.; Case, C.; Miller, K. Developing Smart Toys—From Idea to Product 2001, Intel Technology Journal Q4, 1-9. Available online: https://www.intel.com/content/dam/www/public/us/en/documents/research/2001-vol05-iss-4-intel-t echnology-journal.pdf (accessed on 2 August 2021).

70. Manches, A.; Duncan, P.; Plowman, L.; Sabeti, S. Three questions about the Internet of things and children. TechTrends 2015, 59, 76-83. [CrossRef]

71. Blasius, J.; Greenacre, M. Correspondence Analysis and Related Methods in Practice. In Linear Causal Modeling with Structural Equations; Informa UK Limited: London, UK, 2006; pp. 3-40. Available online: https:/ /www.routledge.com/Linear-Causal-Mo deling-with-Structural-Equations/Mulaik/p/book/9781439800386\# (accessed on 2 August 2021).

72. Gordon, A.D.; Benzecri, J.-P. Correspondence Analysis Handbook. Biometrics 1993, 49, 672. [CrossRef]

73. Johnson, R.A.; Wichern, D.W. Applied Multivariate Statistical Analysis. Biometrics 1998, 54, 1203. [CrossRef] 